\title{
Cloning of Neurotrimin Defines a New Subfamily of Differentially Expressed Neural Cell Adhesion Molecules
}

\author{
Arie F. Struyk, ${ }^{1}$ Peter D. Canoll, ${ }^{2}$ M. J. Wolfgang, ${ }^{1}$ C. L. Rosen, ${ }^{1}$ Peter D'Eustachio, ${ }^{3}$ and James L. Salzer ${ }^{1,4}$ \\ Departments of ${ }^{1}$ Cell Biology, ${ }^{2}$ Pharmacology, ${ }^{3}$ Biochemistry, and ${ }^{4}$ Neurology, New York University Medical School, \\ New York, New York 10016
}

Previous studies in the laboratory indicated that glycosylphosphatidylinositol (GPI)-anchored proteins may generate diversity of the cell surface of different neuronal populations (Rosen et al., 1992). In this study, we have extended these findings and surveyed the expression of GPI-anchored proteins in the developing rat CNS. In addition to several well characterized GPI-anchored cell adhesion molecules (CAMs), we detected an unidentified broad band of $65 \mathrm{kDa}$ that is the earliest and most abundantly expressed GPI-anchored species in the rat CNS. Purification of this protein band revealed that it is comprised of several related proteins that define a novel subfamily of immunoglobulinlike (Ig) CAMs. One of these proteins is the opiate bindingcell adhesion molecule (OBCAM). We have isolated a CDNA encoding a second member of this family, that we have termed neurotrimin, and present evidence for the existence of additional family members. Like OBCAM, with which it shares extensive sequence identity, neurotrimin contains three immunoglobulin-like domains. Both proteins are encoded by distinct genes that may be clustered on the proximal end of mouse chromosome 9. Characterization of the expression of neurotrimin and OBCAM in the developing CNS by in situ hybridization reveals that these proteins are differentially expressed during development. Neurotrimin is expressed at high levels in several developing projection systems: In neurons of the thalamus, subplate, and lower cortical laminae in the forebrain and in the pontine nucleus, cerebellar granule cells, and Purkinje cells in the hindbrain. Neurotrimin is also expressed at high levels in the olfactory bulb, neural retina, dorsal root ganglia, spinal cord, and in a graded dlstrlbution In the basal ganglla and hlppocampus. OBCAM has a much more restricted distribution, being expressed at high levels principally in the cortical plate and hippocampus. These results suggest that these proteins, together with other members of this family, provide diversity to the surfaces of different neuronal populations

\footnotetext{
Received Aug. 1, 1994; revised Sept. 13, 1994; accepted Sept 15, 1994.

We are grateful to Pat Levitt for sharing unpublished sequence data and, together with John Pintar and Marla Luskin, for helpful discussions about the in situ hybridization studies; Bill Lane at the Harvard Microchemical facility for advice on preparation of proteins for microsequencing, and $\mathrm{M}$. Low for his gift of PIPLC. This work was supported by a grant from the American Paralysis Association and the NIH (NS 26001) to J. Salzer. A. Struyk and C. Rosen are Medical Scientist Trainees supported by NIH training grant 5T32 GM07308 from NIGMS. J. Salzer is a recipient of an Irma T. Hirschl Career Scientist Award.

Correspondence should be addressed to Dr. James L. Salzer, Department of Cell Biology, New York University Medical School, 550 First Avenue, New York, NY 10016.

Copyright (C) 1995 Society for Neuroscience $0270-6474 / 95 / 152141-16 \$ 05.00 / 0$
}

that could be important in the specification of neuronal connectivity.

[Key words: glycosylphosphatidylinositol (GPI), neurotrimin, opiate binding-cell adhesion molecule (OBCAM), in situ hybridization, neural cell adhesion molecules, chromosome mapping]

A striking feature of the CNS of higher vertebrates is the exquisite precision with which functionally appropriate neural circuits are established during development. Neurons that reside in widely separated areas extend processes that must successfully navigate distinct cellular environments en route to their synaptic targets. The precision observed in the formation of neuronal projections is thought to result from mechanisms that regulate growth cone pathfinding and target recognition, followed by later refinement and remodeling of these projections by events that require neuronal activity (Goodman and Shatz, 1993). The ability of nerve fibers to make specific pathfinding choices during development and to select their appropriate synaptic target, therefore, underlies the precise patterns of neuronal connectivity observed in the mature nervous system. Emerging evidence indicates that different neurons extend nerve fibers that are biochemically distinct and rely on specific guidance cues provided by cell-cell, cell-matrix, and chemotropic interactions to reach their appropriate synaptic targets (Goodman and Shatz, 1993).

One of the means by which diversity of the neuronal cell surface may be generated is through differential expression of cell surface proteins referred to as cell adhesion molecules (CAMs). Neuronally expressed CAMs have been implicated in diverse developmental processes, including migration of neurons along radial glial cells, providing permissive or repulsive substrates for neurite extension, and in promoting the selective fasciculation of axons in projectional pathways (reviewed in Jessel, 1988; Edelman and Crossin, 1991). Interactions between CAMs present on the growth cone membrane and molecules on apposing cell membranes or in the extracellular matrix, are thought to provide the specific guidance cues that direct nerve fiber outgrowth along appropriate projectional pathways. These interactions are likely to result in the activation of various second messenger systems within the growth cone that regulate neurite outgrowth (Doherty and Walsh, 1992).

In higher vertebrates, most neural CAMs have been found to be members of three major structural families of proteins: the integrins, the cadherins, and the immunoglobulin gene superfamily (IgSF) (Jessel, 1988; Takeichi, 1990; Reichardt and Tomaselli, 1991). Cell adhesion molecules of the IgSF (or IgCAMs), in particular, constitute a large family of proteins frequently implicated in neural cell interactions and nerve fiber 
outgrowth during development (Salzer and Colman, 1989; Brümmendorf and Rathjen, 1993). In some instances, members of the IgSF are believed to function in pathfinding choices. For instance, TAG-1 is expressed in a region where clearly defined pathfinding decisions are being made such as on commissural axons of the spinal cord before crossing the midline (Dodd et al., 1988). Fasciclin II is critical for the formation of the MP1 fascicle in both grasshopper and Drosophila (Grenningloh et al., 1991). However, the majority of mammalian Ig-CAMs appear to be too widely expressed to specify navigational pathways or synaptic targets suggesting that other CAMs, yet to be identified, have a role in these more selective interactions of neurons.

Of the recently identified neural Ig-CAMs, many have becn found to be attached to the plasma membrane via a glycosylphosphatidylinositol (GPI) anchor. Thus, the vertebrate neural proteins TAG-1/axonin-1, F3/F11, Thy-1, and the $120 \mathrm{kDa}$ isoform of NCAM (Tse et al., 1985; He et al., 1986; Gennarini et al., 1989; Furley et al., 1990) and the invertebrate proteins fasciclin I, amalgam, lachesin, and apCAM all exhibit GPI-anchorage (Seeger et al., 1988; Hortsch and Goodman, 1990; Mayford et al., 1992: Karlstrom et al., 1993; reviewed in Salzer et al., in press). In addition, a number of studies have implicated GPI-anchored proteins in providing specific guidance cues during the outgrowth on neurons in specific pathways. In studies of the grasshopper nervous system, treatment of embryos with phosphatidylinositol-specific phospholipase C (PIPLC), which selectively removes GPI-anchored proteins from the surfaces of cells, resulted in misdirection and faulty navigation among subsets of pioneering growth cones, as well as inhibited migratory patterns of a subset of early neurons (Chang et al., 1992). The projection of retinal fibers to the optic tectum appears to depend, in part, on a $33 \mathrm{kDa}$ GPI-anchored protein (Stahl et al., 1990). The precise nature of the GPI-anchored proteins involved in the directional outgrowth in these latter instances is not yet known.

In view of their importance in neural cell interactions, we recently characterized the expression of GPI-anchored proteins by different populations of primary rat neurons in vitro, i.e., sensory neurons of the dorsal root ganglion, sympathetic neurons of the superior cervical ganglion, and cerebellar granule neurons (Rosen et al., 1992). In contrast to the similar pattern of total membrane protein expression by these different types of neurons, striking differences were observed in the expression of GPI-anchored proteins between these neurons. The majority of these proteins were identified, including F3, NCAM-120, and Thy-1. However, a number of the GPI-anchored proteins were not identified; in particular, a prominent and broad band of $65-$ $70 \mathrm{kDa}$. In studies reported here, we have found this protein band is also abundantly expressed in the CNS and is comprised, in part, by a novel neural specific protein with three Ig-like domains that we have termed neurotrimin. Sequence analysis reveals that neurotrimin is highly homologous to the opiate binding-cell adhesion moleculc (OBCAM), which was originally isolated as a potential opiate receptor (Schofield et al., 1989), and genomic Southern analysis reveals that these proteins form a new multigene family of Ig-like CAMs. Their differential patterns of expression suggest that they generate diversity at the neuronal surface that may be significant in the development of specific neural projections.

\section{Materials and Methods}

Detection of GPI-anchored proteins. GPI-anchored proteins wcrc isolated from membrane fractions of different tissues by modifying pre- viously described procedures (Rosen et al, 1992). Tissue was homogenized with either a Dounce or Polytron homogenizer in $10 \mathrm{ml} / \mathrm{mg}$ wet wt in calcium-free PBS containing $1 \mathrm{~mm}$ EDTA and the protease inhibitors antipain, pepstatin $\mathrm{A}$, and leupeptin, all at a concentration of $0.1 \%$ (PE buffer). The homogenate was spun first at $700 \times g$ for 10 min to remove unbroken cells and then at $12,000 \times g$ for $1 \mathrm{hr}$ at $4^{\circ} \mathrm{C}$. The resultant pellet was washed twice in PE buffer at $4^{\circ} \mathrm{C}$, resuspended in $1 \mathrm{ml}$, and the protein concentration was determined by the MicroBCA method following the manufacturer's instructions (Pierce). Membrane protein $(200 \mu \mathrm{g})$ was pelleted in a microfuge and resuspended in calcium-free PBS containing NHS-sulfo-biotin (Pierce) at a concentration of $0.5 \mathrm{mg} / \mathrm{ml}$. Samples were incubated for $30 \mathrm{~min}$ at $4^{\circ} \mathrm{C}$, after which the membranc fractions werc pelleted once more and washed once in Dulbecco's MEM, and three times in calcium-free PE buffer. Pelleted membrane proteins were either used immediately or frozen at $-80^{\circ} \mathrm{C}$ for later use. Subsequent purification of GPI-anchored proteins by release from a Triton-X-114 detergent phase into the aqueous phase by PIPLC treatment and subsequent precipitation with TCA was carried out as previously described (Rosen et al., 1992).

The precipitated proteins were fractionated by SDS-PAGE and electroblotted onto nitrocellulose, which was then blocked with PBS containing $0.5 \%$ Tween-20, $150 \mathrm{~mm} \mathrm{NaCl}, 10 \%$ glycerol, $1 \mathrm{~mm}$ D-glucose $3.5 \% \mathrm{BSA}$, and $2.5 \%$ fat-free dried milk for $1 \mathrm{hr}$ at RT. To detect the GPI-anchored proteins, blots were then incubated with either ${ }^{125}$ I-strep tavidin or alkaline phosphatase-conjugated streptavidin (Bio-Rad) for 1 hr. The blots were rinsed extensively in $0.5 \%$ Tween-20 in PBS, and exposed for autoradiography or developed with the BCIP-NPT substrate (Keirkegaard and Perry), respectively. In some cases, blots were also characterized by incubating with primary antibodies in $0.05 \%$ Tween20 in PBS and then with alkaline phosphatase conjugated to either a goat anti-rabbit or a goat anti-mouse IgG secondary antibody (Cappel). Alkaline-phosphatase conjugated reagents were detected as above.

Neurotrimin purification. A membrane-enriched fraction was prepared from 25 rat brains (Pel-Freeze) as described above. Membrane fractions were solubilized with $40 \mathrm{ml}$ of Triton X-114 extraction solution, and extraction of GPI-anchored proteins was carried out as described above with a proportionate increase in the volumes employed. Proteins released into the aqueous phase upon treatment with PIPLC were separated by SDS-PAGE and electroblotted onto nitrocellulose The blot was stained with Ponceau-S red for $45 \mathrm{sec}$ and rinsed extensively with $1 \%$ acetic acid in deionized water. The glycoprotein band migrating at $65 \mathrm{kDa}$ was excised from the blot and sent to the Harvard Microchemical Facility for protease digestion and internal peptide microsequencing.

Cloning of neurotrimin cDNA. Bovine brain cDNA was a gift of Dr. David Colman (Mt. Sinai Medical Center, New York). PCR on this cDNA was carried out using the Perkin Elmer RT-PCR reagent kit using two degenerate oligonucleotide primers CGAATTCAAYGAYGTIGCIGCICCIGAYGT, corresponding to amino acids 206-212 of neurotrimin and 207-213 of OBCAM, and CGAATTCCCRTCMATIACIGCICCIGGICCRTA, corresponding to amino acids 330-339 of neurotrimin and $331-340$ of OBCAM (where $M$ is an A or C and $I$ is an inosine). Thirtyfive reaction cycles were carried out at $94^{\circ} \mathrm{C}$ for $1 \mathrm{~min}, 45^{\circ} \mathrm{C}$ for $2 \mathrm{~min}$, and $72^{\circ} \mathrm{C}$ for 3 min using 90 pmol of primers per reaction. A PCR product of about 350 base pairs (bp) resulted. This product was digested with EcoRI, subcloned into Bluescript KS (Stratagene) and several clones were sequenced with the Sequenase kit (U.S. Biochemical). Corresponding full length cDNA clones for neurotrimin were isolated from a P5 rat brain library (Stratagene) and plasmid rescue was carried by excision with R408 helper phage. Two full length cDNA clones, referred to as $392 \mathrm{~A}$ and $392 \mathrm{~B}$ were isolated, subcloned into M13mp19, and single stranded DNA sequencing was performed by the dideoxy chain termination method (Sanger et al., 1977) using Sequenase. Sequence analysis and comparisons were carried out using GCG and the Intelligenetics GENEWORKS program.

Generation of antibodies to a neurotrimin fusion protein. A portion of the neurotrimin cDNA corresponding to nucleotides 475-1208 that encodes about two-thirds of the protein was isolated by digestion of pBKS-392B with EcoRI. After filling in the 3' ends with Klenow DNA polymerase to yield blunt ends, the fragment was digested with $P s t \mathrm{I}$ to yield a $739 \mathrm{bp}$ DNA fragment. This fragment was ligated into the pMAL-c vector (New England Biolabs) which had been digested with $X b a I$, filled in with Klenow DNA polymerase, and redigested with PstI. Expression of the fusion protein was induced following manufacturer's instructions. Bacteria were lysed in PBS containing 0.5\% Tween-20, 
and $4 \%$ b-mercaptoethanol (BME) and centrifugated at $10,000 \times g$ for 1 lit. The resultant pellet was solubilized in Laenumli sample buffer and subjected to SDS-PAGE (Laemmli, 1970). The gel was briefly stained with Coomassie blue to identify the fusion protein band. This band was excised, crushed in $200 \mathrm{~mm}$ ammonium acetate and $4 \% \mathrm{BME}$, and incubated for $3 \mathrm{hr}$ at $37^{\circ} \mathrm{C}$. The eluted protein was separated from the polyacrylamide particles by centrifugation for $20 \mathrm{~min}$ at $10,000 \times \mathrm{g}$. It was concentrated by ultrafiltration with a Centricon-30 (Amicon) to 0.5 $\mathrm{mg} / \mathrm{ml}$ prior to injection into rabbits for the production of polyclonal antiserum at a commercial animal facility.

Southern analysis of rat genomic DNA and chromosomal mapping. Rat genomic DNA was prepared from liver as described (Sambrook et al., 1989). A 73 bp probe was generated by PCR from this genomic DNA using the upstream primer (5'-GCGGAGATGCCACCTTTC-3'), and the downstream antisense primer (5'-CACCTGAGGGTGGCGCTC-3'). The reaction products were electrophoresed in a $10 \%$ polyacrylamide gel, and the band was cut out and eluted by the crush and soak method (Sambrook et al., 1989). The fragment was ${ }^{32} \mathbf{P}$ labeled at the $5^{\prime}$ termini by T4 polynucleotide kinase to a specific activity of $6.8 \times 10^{8} \mathrm{cpm} / \mu \mathrm{g}$. This was used to probe genomic DNA that had been digested overnight with a series of restriction enzymes (New England Biolabs), separated by agarose gel electrophoresis and blotted onto a nylon membrane (Genescreen, New England Nuclear). After hybridization, the blot was washed for $5 \mathrm{~min}$ each in $2 \times \mathrm{SSC} / 0.5 \% \mathrm{SDS}$ at $20^{\circ} \mathrm{C}$, $2 \times \mathrm{SSC} / 0.1 \% \mathrm{SDS}$ at $20^{\circ} \mathrm{C}, 0.1 \times \mathrm{SSC} / 0.5 \% \mathrm{SDS}$ at $37^{\circ}$, and $0.1 \times$ SSC $/ 0.5 \%$ SDS at $65^{\circ}$.

For chromosomal mapping, STS/A and O20/A inbred mice, and OXA and CXS recombinant inbred (RI) mice were obtained from J. Hilgers (The Netherlands Cancer Institute). All other standard inbred and recombinant mice were obtained from The Jackson Laboratory. Progeny of a reciprocal backcross between $\mathrm{C} 57 \mathrm{BL} / 6 \mathrm{~J}$ and SWR/J mice have been previously described (Blank et al., 1998). To type mice for restriction fragment length variants detected by the $\mathrm{pXYZ}$ neurotrimin probe, genomic DNA isolated from livers was digested with EcoRI and analyzed by Southern blotting (Blank et al., 1998). To establish genetic linkages between Ntmn and other markers typed in RI mice, strain distribution patterns observed for Ntmn were compared to those for approximatcly 1975 other markers maintained in a databasc at NYU (D'Eustachio, P., unpublished). The significance of pair-wise matches was assessed using the BAYLOC algorithm (Blank et al., 1998).

Northern analysis of neurotrimin mRNA expression. Total cellular RNA was isolated by homogenizing tissue in phenol/guanidium thiocyanate/chloroform (RNAzol, Cinna/Biotecx Laboratories) and precipitation from the aqueous phase with isopropanol as per the manufacturer's instructions. Thirty micrograms of RNA per sample were electrophoresed through a denaturing formaldehyde gel (Sambrook et al., 1989), blotted onto nylon membranes (Genescreen, NEB), and fixed by UV irradiation. A neurotrimin cDNA probe, extending from nucleotide $\# 1296$ to the $3^{\prime}$ end, was labeled with ${ }^{32} \mathrm{P}$ by random priming using a commercially available kit (Boehringer-Mannheim). Hybridization of the labeled probe and washing of membranes was carried out as described (Sambrook et al., 1989).

In situ hybridization. Brains from rats of different postnatal ages or whole E18 rat embryos were dissected. For E18 to P10 ages, samples were first immersed in 4\% paraformaldehyde in PBS at RT for $4 \mathrm{hr}$, then incubated overnight in $20 \%$ sucrose in PBS at $4^{\circ} \mathrm{C}$ before being frozen on dry ice. For ages P14 and above, brain samples were fresh frozen on dry ice. In both cases, 15 micron cryostat sections were prepared, thaw mounted on gelatin-coated glass slides, and fixed in $4 \%$ paraformaldehyde in PBS. After extensive washing in PBS, the mounted sections were dehydrated through an alcohol series $(5 \mathrm{~min}$ each in $60 \%$, $80 \%, 95 \%$, and $100 \%$ ), and frozen at $-70^{\circ} \mathrm{C}$ for later use.

Antisense probes complementary to ncurotrimin (AGGTCACACAGTGCAGCTTGTGGGTGGGTCCAAGCTAGGTGCGCCTTCTTCC) and (AGGAGCAGGTGTAAGACCAGAAGAGGGAGGAGCCAAATGCAGCCTGCCCT) or to OBCAM (ATGAAGAAGTGGGCAAAGAAGGTCCCTGAGAGCCAGAGACAAGCC) and (GTGTACTGCACTGTGGGCCAAGTTGTACCTTCAGGGTGCGTGTCATGGGA) were synthesized and labeled with ${ }^{35} \mathrm{~S}$-labeled dATP by terminal dideoxy transferase reaction to a specific activity of $0.75-1.5 \times 10^{8} \mathrm{cpm} /$ $\mu \mathrm{g} .4 \times 10^{6} \mathrm{cpm}$ of each probe were included in the hybridization buffer for each slide. Hybridization was carried out at $42^{\circ} \mathrm{C}$ overnight in $50 \%$ formamide, $4 \times$ SSC, $1 \times$ Denhardt's, $100 \mu \mathrm{g} / \mathrm{ml}$ denatured salmon sperm DNA, $50 \mu \mathrm{g} / \mathrm{ml}$ yeast tRNA, $10 \%$ dextran sulfate, and $10 \mathrm{~mm}$ DTT. After removal of the hybridization solution, slides were rinsed briefly in $2 \times \mathrm{SSC}$, followed by three 30 min washings in $2 \times \mathrm{SSC}$ at room temperature and one 30 min washing in $1 \times \mathrm{SSC}$ at $50^{\circ} \mathrm{C}$, and one $30 \mathrm{~min}$ washing in $0.5 \times \mathrm{SSC}$ at $50^{\circ} \mathrm{C}$, followed by a brief rinse in $0.5 \times \mathrm{SSC}$ at RT. Slides were dehydrated through an alcohol series $(60 \%, 80 \%, 95 \%$, and $100 \%$, each containing $200 \mathrm{~mm}$ ammonium acetate). Slides were first exposed to $\mathrm{x}$-ray film, and then dipped in K5 autoradiographic emulsion (Ilford) for autoradiography and processed as described (Levy et al., 1993).

\section{Results}

\section{Expression of GPI-anchored proteins in the CNS}

In previous studies, we described the expression of GPI-anchored proteins in different populations of primary neurons (Rosen et al., 1992). The major protcin band expressed by cerebellar granule cells and sensory neurons of the dorsal root ganglion migrated with a molecular weight of $65-70 \mathrm{kDa}$. This band did not cross-react with antisera to a variety of known neural GPIanchored proteins and, thus, appeared to be novel (Rosen et al., 1992). To further characterize this $65 \mathrm{kDa}$ protein band, including identifying a potential source for its purification, we examined its expression in different tissues and its spatial and temporal expression in the nervous system. To this end, we extracted GPI-anchored proteins from different tissues by modifying our previous protocol (Rosen et al., 1992). Briefly, total membrane fractions were prepared, biotinylated, and solubilized in Triton $\mathrm{X}-114$. Integral membrane proteins were partitioned into the detergent phase, which was treated with PIPLC to release GPIanchored proteins into the aqueous phase. The GPI-anchored proteins were then fractionated by SDS-PAGE and visualized, after blotting, with ${ }^{125}$ I streptavidin.

We first compared the pattern of GPI-anchored protein expression in different tissues to determine whether expression of the $65 \mathrm{kDa}$ band is restricted to the nervous system. We isolated GPI-anchored proteins from adult rat brain, liver, lung, spleen, cardiac muscle, skeletal muscle, intestine, and kidney (Fig. 1). The overall pattern of expression of GPI-anchored proteins differs strikingly in these tissues. Notably, the CNS appears to be a rich source of GPI-anchored proteins and the major proteins appear to correspond to those previously found to be expressed by purified populations of sensory neurons (Rosen et al., 1992) suggesting they are principally of neuronal origin. Specifically, three major bands were observed in the brain: a slowly migrating band with an MW of 120-135 kDa (which frequently resolved as a doublet), a broad band of $65-70 \mathrm{kDa}$, and a band of 27 $\mathrm{kDa}$ (Fig. 1, lane a). A similar pattern of GPI-anchored protein expression was observed in all regions of the adult rat CNS surveyed including the cerebellum, optic nerve, olfactory nerve, brainstem, and spinal cord (data not shown). By Western blot analysis, we determined that the $120 \mathrm{kDa}$ band, which is also seen in spleen and kidney, and at low levels in lung and skeletal muscle, corresponds to the GPI-anchored form of NCAM. By Western blotting we also found that the upper portion of this band, with an MW of $135 \mathrm{kDa}$, corresponds in part to F3 (data not shown). TAG-1, which has a similar electrophoretic mobility (Furley et al., 1990) may also comigrate with this band. The lower $27 \mathrm{kDa}$ band was presumptively identified as Thy-1, based on its abundant expression in the CNS and its molecular weight. Notably, Thy-1 and the $65 \mathrm{kDa}$ protein band appears to be expressed principally within the nervous system, as no corresponding protein bands were identified in the other tissues examined. Other GPI-anchored proteins known to be expressed in the nervous system, including the oligodendrocyte-myelin glycoprotein (Mikol et al., 1990) and T-cadherin (Ranscht and Dours-Zim- 


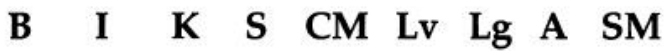

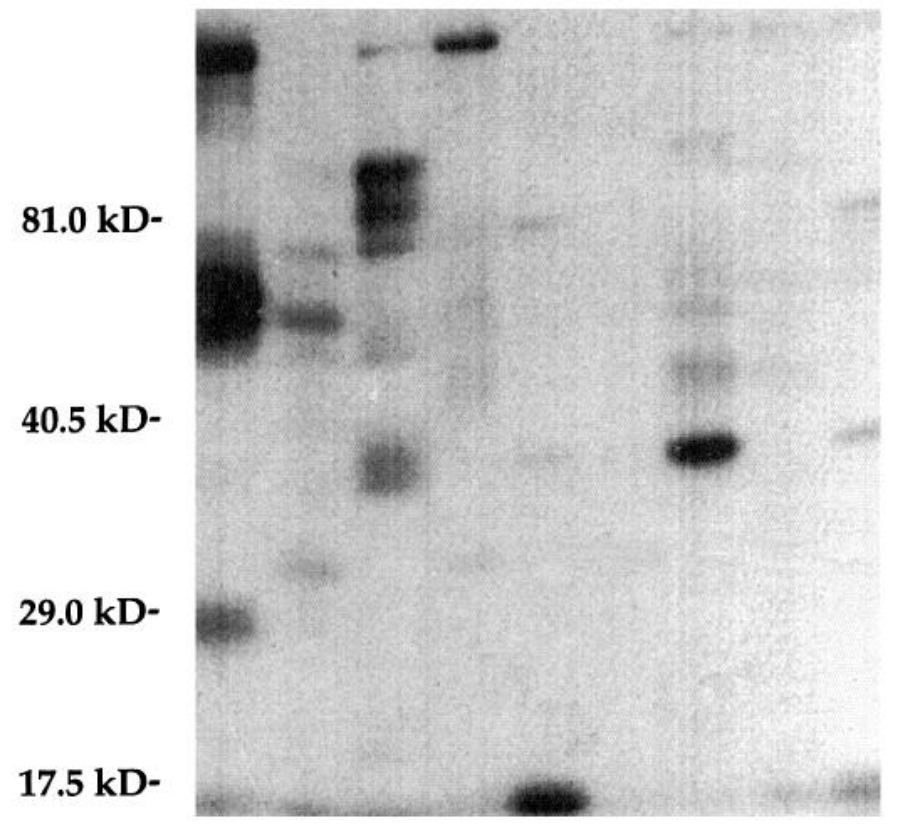

Figure 1. Tissue-specific expression of GPI-anchored proteins. GPIanchored proteins were isolated from brain $(B)$, intestine $(I)$, kidney $(K)$, spleen $(S)$, cardiac muscle $(C M)$, liver $(L v)$, lung $(L g)$, adrenal gland $(A)$, and skeletal muscle $(S M)$ of an adult rat. Samples were electrophoresed, blotted, and probed with ${ }^{125}$ I-streptavidin. Note that a 65 $\mathrm{kDa}$ protein band predominates in the brain and appears to be absent in the other tissues surveyed. Molecular weight markers are indicated at left.

merman, 1991), were not identified in these samples and, therefore, appear to be less abundant proteins.

To further characterize the $65 \mathrm{kDa}$ protein, we determined the time course of its expression. We performed a developmental survey of GPI-anchored protein expression in the cerebrum between embryonic day 15 and the adult (Fig. $2 A$ ). As previously described (Gennarini et al., 1989), F3 is seen arising at around E17, and Thy-1 and the GPI-anchored form of NCAM appear between P5 and P30. It is of note that the earliest GPI-anchored protein to appear in abundance is the $65 \mathrm{kDa}$ band, which is readily detectable by E15. The expression level of this $65 \mathrm{kDa}$ species appears to peak during the first postnatal week and declines thereafter, although at all times it appears to be more abundant than F3/F11, the GPI-anchored form of NCAM, and Thy-1. A similar pattern of expression was also observed in the cerebellum, where this band predominates at all time points (data not shown).

These findings are complicated in part because, as is true of DRG neurons (Rosen et al., 1992), the $65 \mathrm{kDa}$ band appears to be comprised of two different polypeptides species that comigrate. Thus, after enzymatic deglycosylation, the $65 \mathrm{kDa}$ GPIanchored protein fraction from cerebellum and cerebrum also resolved as a major $39 \mathrm{kDa}$ polypeptide band and, to a lesser extent, a $55 \mathrm{kDa}$ band (data not shown). In other studies, we have determined that the upper portion of the $65 \mathrm{kDa}$ protein band, with a core polypeptide size of $55 \mathrm{kDa}$, corresponds to the receptor for ciliary neurotrophic factor (C. Rosen and J. Salzer, unpublished results), which is known to be GPI-anchored

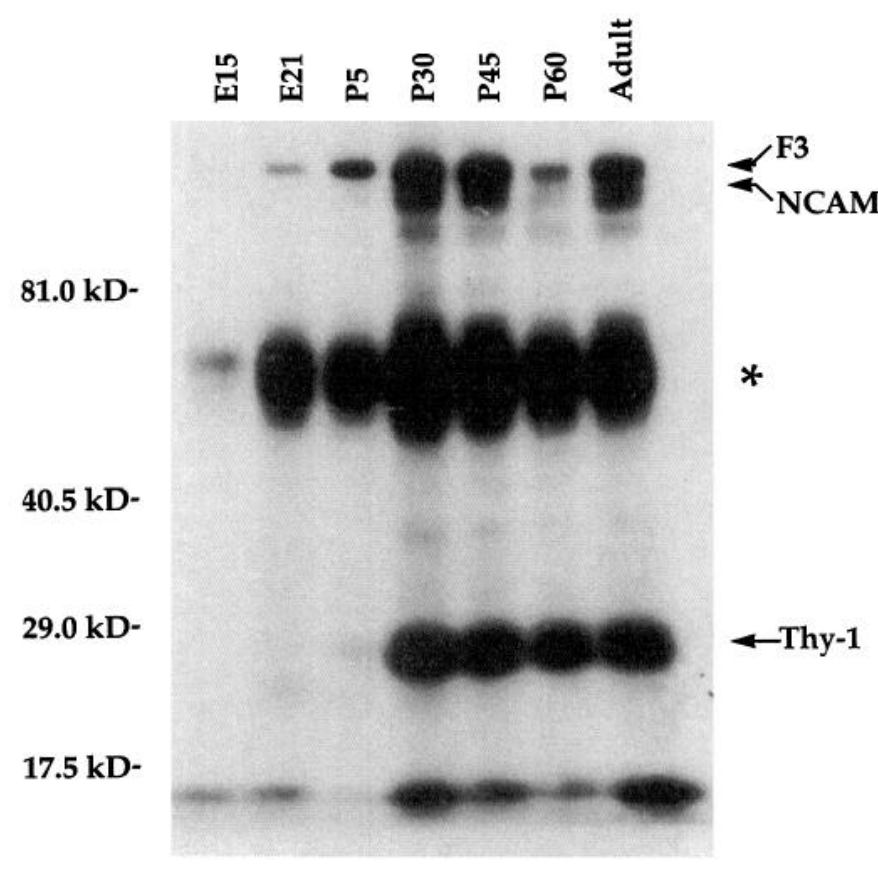

81.0 kD-

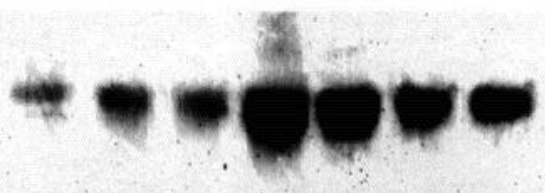

40.5 kD-

Figure 2. Developmental expression of GPI-anchored proteins in the cerebrum. A (upper panel), GPI-anchored proteins were isolated from the cerebrums of rats of different embryonic $(E)$ or postnatal $(P)$ ages, as indicated at top. Samples were electrophoresed, blotted, and probed with ${ }^{125}$ I-streptavidin. Protein bands corresponding to F3, NCAM, and Thy -1 are indicated at right. The $65 \mathrm{kDa}$ protein (indicated by the asterisk at the right) is the first and most abundant GPI-anchored protein expressed in the cerebrum. Molecular weight markers are indicated at the left. $B$ (lower panel), The blot shown in $A$ was probed with antiserum raised to a neurotrimin fusion protein. The embryonic age $(E)$ or postnatal age $(P)$ of each sample is indicated at top of each lane. The antiserum recognizes a band as early as E15, which is developmentally regulated, increasing through early postnatal ages and declining in the adult. In all samples, the antiserum recognizes only the lower portion of the $65 \mathrm{kDa}$ protein band present in $A$. Molecular weight markers are indicated at the left.

(Davis et al., 1991). The $39 \mathrm{kDa}$ polypeptide species is described further below.

\section{cDNA cloning of neurotrimin, a novel member of the immunoglobulin gene superfamily}

In order to determine the identity of the major component of the $65 \mathrm{kDa}$ protein band (gp65), we scaled up the GPI-anchored protein extraction to isolate sufficient protein for peptide microsequencing. We extracted, gel purified, and blotted approximately $5 \mu \mathrm{g}$ of the $65 \mathrm{kDa}$ protein band onto nitrocellulose. The band was excised, and subjected to V8 protease digestion and subsequent internal peptide microsequencing. Amino acid sequence data was obtained for two peptides, (DQSGEYECSALNDVAAPDVR) and (VTVNYPPYISEAK), both of which showed significant homology to the opiate binding-cell adhesion 
molecule (OBCAM), an IgSF member isolated from bovine brain (Schofield et al., 1989). The former peptide showed 100\% identity over 20 amino acids to bovine OBCAM, while the latter differed in 3 positions out of 13 . These findings suggested that the $65 \mathrm{kDa}$ protein band is comprised of the rat homolog of OBCAM and/or closely related proteins.

To further characterize rat gp65, including its relationship to OBCAM, we isolated its corresponding cDNA. An upstream degenerate oligonucleotide corresponding to a portion of the sequence of the first peptide and a downstream primer complementary to amino acids 312 to 319 of the bovine OBCAM sequence (Schofield et al., 1989) were synthesized. We used these primers to amplify PCR products from a bovine brain cDNA template, and identified two distinct products of the predicted $350 \mathrm{bp}$ size. The first product was identical to the corresponding region of bovine OBCAM. The sequence of the second PCR product was novel but highly homologous (67\% identical) to OBCAM throughout its length. Conceptual translation of this second CDNA sequence indicated that it encoded a polypeptide with $>60 \%$ identity to the comparable sequence of bovine OBCAM.

We used this second PCR product to isolate a corresponding full-length cDNA clone from a rat brain library. We obtained several cDNA clones with identical $3^{\prime}$ ends, the two longest of which were found to contain a single 1038 bp open reading frame encoding a protein of 344 amino acids (Fig. 3). The N-terminal 31 amino acids are quite hydrophobic and are likely to correspond to a signal sequence, with cleavage predicted to occur at Arg32 (arrowhead, Fig. 3). The C-terminus also contains a hydrophobic sequence of 18 amino acids (underlined, Fig. 3), consistent with a GPI-anchor attachment signal. Based on attachment signals in other proteins (Kodukula et al., 1993), the two most favorable sites for GPI-anchor attachment are Asn320 and Gly322. Like OBCAM, it contains three C2-like immunoglobulin domains. In view of its specific expression by neurons (see below), and its three immunoglobulin-like domains, we have termed this protein neurotrimin.

Detailed comparison of the peptide sequences of neurotrimin to that of rat OBCAM, which was recently reported (Lippman et al., 1992), indicates that the two proteins are 77\% identical overall. The highest homology between these proteins is shared by their first Ig-domains, which are $94 \%$ identical (Fig. 4). This represents only eight substitutions within a stretch of about 120 amino acids, despite considerable alternate codon usage through much of this region. Neurotrimin has eight potential $\mathrm{N}$-linked glycosylation sites (marked by asterisks, Fig. 3), two more than OBCAM. Like OBCAM, neurotrimin has three sets of cysteines that are likely to form intradomain disulfide linkages in each of its immunoglobulin-like domains. In addition, neurotrimin possesses an extra cysteine at position 83, whereas OBCAM contains a serine at this position (marked by an asterisk in Fig. 4). This extra cysteine was confirmed in the sequence of two independent neurotrimin cDNA clones; it could potentially form an intermolecular disulfide bond, although its physiologic significance is not yet known.

A homology search of the Swissprot database with the neurotrimin amino acid sequence reveal that, like OBCAM, neurotrimin demonstrates highest homology to a number of wellcharacterized neural Ig CAMs, including NCAM, F3/F11/contactin, L1/NILE, and MAG (Table 1). The regions of highest homology to most of these proteins occurs in the conserved sequences surrounding the cysteines involved in intradomain di- sulfide bonding and in the folding of the beta-sheets. Domains 2 and 3 of both neurotrimin and OBCAM show highest similarity to domains 4 and 3 of NCAM, respectively. Interestingly, domain 1 of each protein shows the highest homology to the Iglike domain 1 of the basic FGF receptor for (Reid et al., 1990) but also shows significant homology to several neural Ig-CAMs.

Neurotrimin and $O B C A M$ are part of a multigene family that is located on murine chromosome 9

Comparison of the neurotrimin cDNA sequence to that of rat OBCAM suggested that these proteins are likely to be encoded by different genes rather than being alternative spliced from a single RNA transcript. In particular, there is no extended region of sequence identity throughout most of the $5^{\prime}$ or any of the $3^{\prime}$ noncoding regions. One region that is an exception extends between nucleotides 456 and 653 in neurotrimin cDNA and 270 and 467 in rat OBCAM cDNA and shows a remarkable degree of nucleotide identity, i.e., $98 \%$. This region spans the start codon of each protein and extends through the amino-terminal signal sequence. These finding raised the possibility that rat $\mathrm{OB}-$ CAM and neurotrimin could be products of a single gene that is extensively alternatively spliced.

In order to determine whether at least two copies of this sequence are found in the rat genome, which would be consistent with separate genes encoding neurotrimin and OBCAM, we performed genomic Southern analysis. Primers bracketing part of the region of identity were synthesized (indicated by arrows in Fig. 3) and used to amplify the corresponding segment from rat genomic DNA. On PAGE, the resultant PCR product ran at the predicted 73 bp size, indicating that the primers do not span an intron/exon boundary. This $73 \mathrm{hp}$ exonic fragment was used, in turn, to probe a Southern blot of rat genomic DNA digested with several different restriction enzymes (Fig. 5). We observed multiple bands in each lane. In some digests such as BamHI, up to five bands were observed (shown by the arrowheads in lane e), indicating that this 73 bp region is repeated as many as five times throughout the rat genome. This finding is consistent with the hypothesis that distinct genes encode neurotrimin and OBCAM, and strongly suggest that additional related genes, yet to be identified, are present in the genome. Indeed, in other studies in which we performed PCR with degenerate primers using a rat brain cDNA template, we identified a third member of this family that demonstrates approximately $55 \%$ amino acid identity to both neurotrimin and OBCAM (O. Gil, G. Zanazzi, and J. Salzer, unpublished and sec below).

To localize the gene for neurotrimin on the murine chromosome, Southern blotting of EcoRI-digested genomic DNA from inbred strains of mice was performed. This analysis revealed four bands reactive with rat neurotrimin, three of which were constant in size and one whose size varied between strains. Inheritance of the variant was followed in RI mice (Tables 2,3) and in progeny of a backcross between the inbred strains C57BL/6J and SWR/J. Comparison of the strain distribution patterns for the neurotrimin DNA variant with those previously determined for other markers defined a locus, Ntmn, on proximal chromosome 9 near Ets1 ( 2 of 21 RI strains typed for both markers were recombinant, as were 3 of 65 backcross progeny, for estimated distances between the markers of 2.8 and $4.6 \mathrm{cM}$, respectively). Comparison of the RI typing data for Ntmn, Ets1, and other markers of chromosome 9 supports the placement of Ntmn proximal to EtsI (see Table 3). It is not yet known whether the genomic DNA fragments that were invariant in these map- 
1 CAA CTT AAG AAA GTG CTG GAT TTC CCG TTG TTC GAT TGA GGA ACC GTA GAC CAC ATC TGG 61 GTA GCT GCA TTC ACC CCA GCC ACA GCC CCG TTG GAT ACC AAA GTG CTT ACT CCT GTC CAA 121 AGT GCC ATG CCT GAA CTG CTA CGG GGA AGA GGC AGC TTC TGA GAC CCG CAC CTG TGC GCC 181 TGC TTG CCT GCC TTG CGC TTC TCT CTC CTG GCC ACC TTC CTG GCC ACA GGC AGC ACG GAG 241 AAA GTC CGC CTC GGA TGT GTG TGG AAA CTG GTT CTC $\Lambda$ GA GGC TGC GAG CTG AGG CTG GAT 301 TTA GGG GAG GAA TAT TAG ACT TGG AGG AGT CTG CGC GCT TTT CTC CTC CCA GTG CAT CGC 361 GCG GTC GCC GCT AGT TCA TCG CTG GGT CCC CGC GCT CAC TCC CCA CCC CAC CCA CTT CCT 421 GTG CTC GCC CGG GGG GCG TGT GCG TGC CAC TAC CGG AGT TCT GGG AAG TTG TGG CTG TCG

481 AgA ATG GGG GTC TGT GGG TAC CTG TTC CTG CCC TGG AAG TGC CTC GTG GTC GTG TCT CTC 1 met gly val cys gly tyr leu phe leu pro trp lys cys leu val val val ser leu

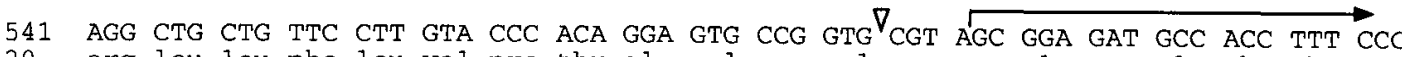
20 arg leu leu phe leu val pro thr gly val pro val arg ser gly asp ala thr phe pro

601 AAA GCT ATG GAC AAC GTG ACG GTC AGG CAG GGG GAG AGC GCC ACC CTC AGG TGC ACA ATT 40 lys ala met asp asn val thr val arg gln gly glu ser ala thr leu arg cys thr ile

661 GAC AAC CGA GTC ACC CGG GTG GCC TGG CTA AAC CGC AGT ACC ATC CTC TAT GCT GGA AAT 60 asp asn arg val thr arg val ala trp leu asn arg ser thr ile leu tyr ala gly asn

721 GAC AAG TGG TGC CTA GAT CCT CGT GTG GTT CTC CTG AGT AAC ACC CAG ACC CAG TAC AGC 80 asp lys trp CyS leu asp pro arg val val leu leu ser asn thr gln thr gln tyr ser

781 ATT GAG ATC CAG AAT GTG GAT GTG TAT GAT GAG GGC CCT TAT ACC TGC TCG GTG CAG ACA 100 ile glu ile gln asn val asp val tyr asp glu gly pro tyr thr cys ser val gln thr

841 GAC AAC CAC CCT AAG ACC TCC AGG GTC CAC CTC ATT GTA CAA GTA TCT CCC AAA ATT GTA 120 asp asn his pro lys thr ser arg val his leu ile val gln val ser pro lys ile val

901 GAG ATT TCT TCA GAT ATC TCC ATT AAT GAA GGg AAC AAC ATC AGC CTC ACT TGC ATA GCC $140 \mathrm{glu}$ ile ser ser asp ile ser ile asn glu gly asn asn ile ser leu thr cys ile ala

961 ACA GGT AGA CCG GAG CCT ACA GTA ACC TGG AGA CAT ATT TCT CCC AAA GCT GTC GGC TTT 160 thr gly arg pro glu pro thr val thr trp arg his ile ser pro lys ala val gly phe

1021 GTG AGT GAG GA' GAG TAC C'I'G GAG ATC CAG GGC ATC ACT CGG GAG CAG TCA GGC GAG TAT 180 val ser glu asp glu tyr leu glu ile gln gly ile thr arg glu gln ser gly glu tyr 1081 GAG TGC AGC GCC TCC AAC GAC GTG GCA GCA CCA GTC GTA CGA AGA GTG AÁ G'L ACC GTG 200 glu cys ser ala ser asn asp val ala ala pro val val arg arg val asn val thr val

1141 AAC TAT CCA CCA TAC $\Lambda T C$ TCA GAA GCT AAG GGT ACA GGT GTC CCC GTG GGG CAG AAG GGG 220 asn tyr pro pro tyr ile ser glu ala lys gly thr gly val pro val gly gln lys gly

1201 ACT CTG CAG TGT GAA GCC TCG GCA GTC CCT TCA GCA GAA TTT CAG TGG TTC NAG GAT GAC 240 thr leu gln cys glu ala ser ala val pro ser ala glu phe gln trp phe lys asp asp

1261 AAA AGA CTG GTD GAA GGG AAG AAG GGA GTC AAA GTG GAA AAC AGA CCT TTC CTT TCA AGA 260 lys arg leu val glu gly lys lys gly val lys val glu asn arg pro phe leu ser arg 1321 CTC ACC TTT TTC AÄ GTC TCT GAA CAC GAC TAT GGG AÁC TAC ACA TGT GTG GCA TCC AAC 280 leu thr phe phe asn val ser glu his asp tyr gly asn tyr thr cys val ala ser asn 1381 AAG TTG GGC CAC ACC AÄT GCC AGC ATC ATG CTA TTT GGC CCA GGT GCT GTC AGC GAG GTC 300 lys leu gly his thr asn ala ser ile met leu phe gly pro gly ala val ser glu val 1441 AAC AÂT GGG ACG TCA AGG AGG GCA GGC TGC ATT TGG CTC CTC CCT CTT CTG GTC TTA CAC 320 asn asn gly thr ser arg arg ala gly cys ile tro leu leu oro leu leu val leu his

1501 CTG CTC CTC AAA TTT TGA TGT GAG TGC CCC TTC CCT GCC GGG GAG AGC TGC TGC CAC CGC 340 leu leu leu lys phe OPA

1561 ATC TCA ATT CAA CAG CAC TGC AAC ATG AAG CAA CAA GTC AGA ATC AAA TGA AAT TCC GAG 1621 AAT CAC AGC CAA TGA GAC AGA AAT TCG AGG GAG GGG AAC AAA GCA TAC TGT GGT AAA GGG 1681 GAA AAA AAA AGT CTA AAA AAA GGA AAT TTG AAA ATT GCC TTG CAG ACA TTT CGG TAC CAC 1741 TGA GTT TTC TTT CTT TTC CCA AAT GGG AAG AAG GCG CAC CTA GCT TGG ACC CAC CCA CAA 1801 GCT GCA CTG TGT GAC CTC TCT GTT GCC AGG GTG GGC AAG GGC TCA GCC ACT CTG CCC ACT

1861 AAA GTG CCC CAC CAT GGA ACA TTC TGG AGT CGG CCA TCC CAA ATT TCA TCG GTC CAT AGA 1921 CAC AAG CAC AGA GTG AGA AAC AGG GGC CCA GAA GTG CCA CGG AGG GCC CTT TGG TGG GCT 1981 GCG CGA TGG TGG CGT GTG TCA TGA AGT GTG AAA TCC GAA GTA GAA AAA AAA CAA GAA TAA 2041 AAA AAA AAA AAA AA

Figure 3. cDNA sequence of neurotrimin. A 2054 hp cDNA containing the full-length neurotrimin coding region was isolated and sequenced. The deduced amino acid sequence underlies the codons of the coding region. An arrowhead overlies the predicted site of signal sequence cleavage after translocation through the ER membrane. The six cysteines that are likely to form intradomain disulfide bonds are shown in boldface. The seventh cysteine present in the mature polypeptide available for intermolecular disulfide bond formation is boxed. The cight potential N-linked glycosylation sites are marked with asterisks. The hydrophobic C-terminal sequence specifying GPI-anchored attachment is underlined. Arrows overlie flanking sequences to which complementary oligonucleotides were designed for use in PCR from rat genomic DNA (GenBank accession no. U16845). 


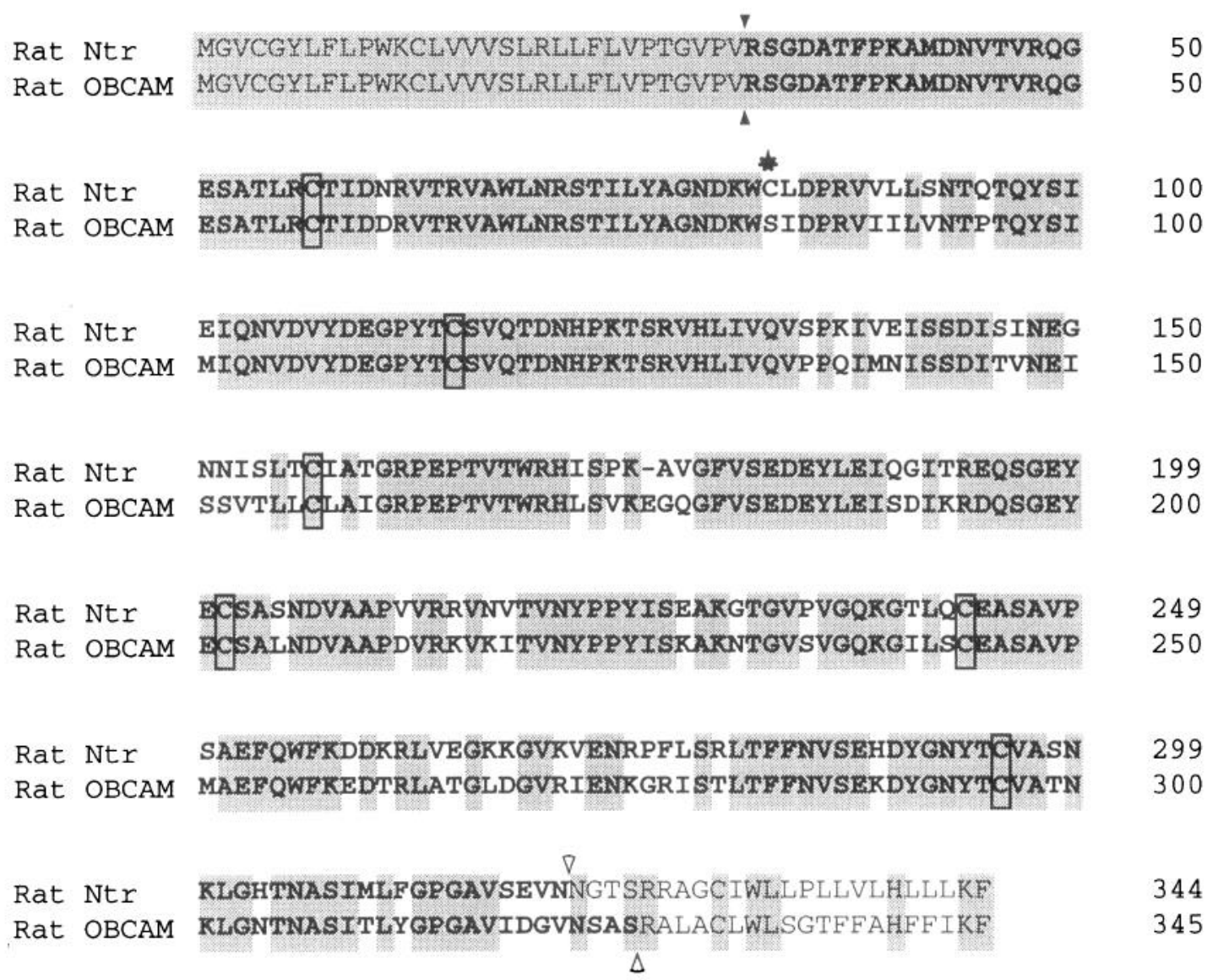

Figure 4. Comparison of the peptide sequences of neurotrimin and OBCAM. The deduced amino acid sequences of neurotrimin and rat OBCAM (Lippman et al., 1992) are aligned and identical amino acid residues shared between these two proteins are shaded. The six cysteines in each protein involved in intradomain disulfide bond formation are boxed. The extra cysteine present in neurotrimin but absent in OBCAM is marked by an asterisk. The sites of amino-terminal signal sequence cleavage and carboxy-terminal GPI-anchor attachment are indicated with arrowheads for each protein. The probable mature polypeptide region for each protein, based on published predictions for signal sequence cleavage (Heijne, 1986) and for GPI-anchor attachment (Kodukula et al., 1993), is listed in boldface.

\section{Table 1. Homology of neurotrimin to other members of the immunoglobulin gene superfamily}

\begin{tabular}{lcclll} 
Protein & $\begin{array}{l}\text { Region of } \\
\text { similar protein }\end{array}$ & $\begin{array}{c}\text { Region of } \\
\text { neurotrimin }\end{array}$ & \% Identity & Opt. score & $Z$ value \\
\hline NCAM & $190-502$ & $40-317$ & 25.7 & 287 & 49.6 \\
MAG & $234-431$ & $130-330$ & 28.2 & 226 & 34.9 \\
Axonin-1 & $290-503$ & $99-310$ & 28.0 & 222 & 38.8 \\
Ng-CAM & $108-359$ & $12-255$ & 22.4 & 218 & 31.9 \\
F3 & $311-605$ & $43-315$ & 21.0 & 180 & 48.1 \\
K flt receptor & $621-783$ & $186-341$ & 25.9 & 166 & 23.5 \\
L1 & $207-500$ & $2-299$ & 20.4 & 151 & 30.7 \\
MLCK & $1-174$ & $149-310$ & 24.0 & 149 & 34.3 \\
Amalgam & $102-222$ & $185-309$ & 27.0 & 136 & 22.3 \\
Poliovirus receptor & $17-359$ & $7-342$ & 20.8 & 121 & 24.1 \\
bFGF receptor & $7-80$ & $8-82$ & 25.3 & 94 & 26.8
\end{tabular}

A search of the Swissprot database with the deduced amino acid sequence of neurotrimin using the FASTA program reveals significant similarity to members of the immunoglobulin superfamily. In addition to rat and bovine OBCAM, which are not listed, the 12 most similar proteins are, in order of their optimized scores, mouse NCAM (Barthels et al., 1987), rat S- and L-MAG (Salzer et al., 1987), human axonin-1 (Hasler et al., 1993), chick Ng-CAM (Burgoon et al., 1991), mouse F3 (Gennarini et al., 1989), human K ft tyrosine kinase receptor (Shibuya et al., 1990), mouse L1 (Moos et al., 1988), chick nonmuscle myosin light chain kinase, MLCK (Shoemaker et al., 1990), Drosophila amalgam (Seeger et al., 1988), human poliovirus receptor (Mendelsohn et al., 1989), and the mouse basic FGF receptor (Reid et al., 1990). Percentage of identical amino acid residues between the similar regions of each related protein (third column) and neurotrimin (fourth column) are shown. The significance of the similarity is given by the $Z$ value, which was calculated on the basis in Initn scores calculated from the FASTA search (not shown). $Z$ values $>6$ are probably significant; those $>10$ are considered definitely significant (Lipman and Pearson, 1985). 


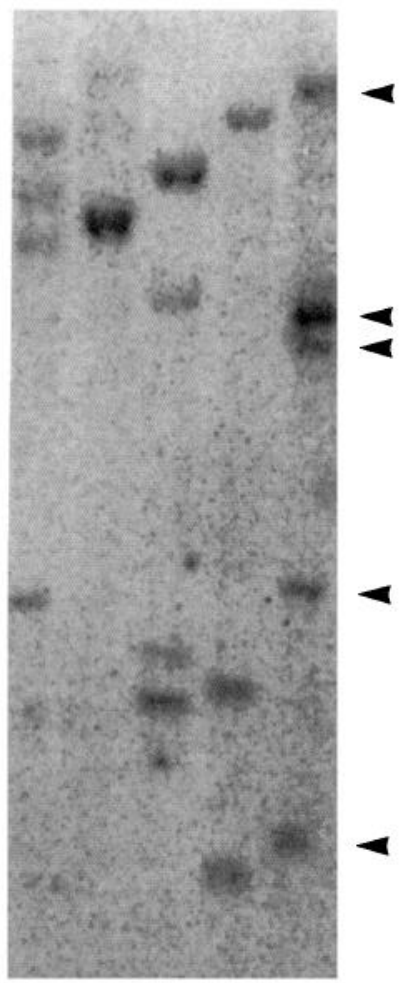

a $\quad$ b $\quad c \quad d \quad e$

Figure 5. Southern blot of genomic DNA with a common sequence from neurotrimin and OBCAM cDNAs. Rat genomic DNA was digested with HindIII (a), EcoRI (b), HincII (c), PstI (d), and BamHI (e), electrophoresed, and Southern blotted onto a nylon membrane. This blot was probed with a $73 \mathrm{bp}$ PCR product corresponding to an exonic fragment as described in the Materials and Methods. Note that five bands are seen after BamHI digestion (indicated with arrowheads to the right) and three to four are seen in the other lanes, including lane $b$, which contains several faint bands near the top of the gel.

ping studies represent other regions of Ntmn, or whether they represent additional linked or unlinked members of a Ntmn gene family as suggested by the Southern blot in Figure 5 .

\section{Analysis of neurotrimin expression}

To determine the relative contribution of neurotrimin to the broad $65 \mathrm{kDa}$ band, we raised a polyclonal antiserum to a neu-

\begin{tabular}{|c|c|c|c|c|}
\hline Marker & $\mathrm{Chr}$ & $\mathrm{R} / \mathrm{N}$ & Probability & Distance $(95 \%$ lim) \\
\hline Ets 1 & 9 & $2 / 21$ & 0.01625 & $2.8(0.3-13.0)$ \\
\hline Apoa1 & 9 & $3 / 17$ & 0.41281 & $6.0(1.0-31.1)$ \\
\hline $\mathrm{Up} 2$ & 9 & $8 / 35$ & 00.15616 & $8.7(3.1-25.2)$ \\
\hline
\end{tabular}

${ }^{a}$ The strain distribution pattern for the Ntmn restriction fragment length variant was compared to ones for 464 markers previously typed in the same RI strains. For each match shown, the marker's name and chromosomal location are shown, together with the observed recombination fraction $(R / N)$, probability of observing that fraction or a smaller one by chance (Blank et al., 1998), and, conditional on the existence of linkage, the estimated distance in centimeters between the two loci (Taylor, 1978), and the $95 \%$ binomial confidence limits for that estimate (Silver, 1985).

rotrimin bacterial fusion protein. This antiserum, which appears to recognize a linear epitope (i.e., it reacts with blots but not tissue sections), was used to probe the developmental surveys of GPI-anchored proteins in the cerebellum and cerebrum described previously. The antiserum recognized a portion of the $65 \mathrm{kDa}$ protein band at all ages in both the cerebrum (Fig. $2 B$ ) and cerebellum (data not shown). In the cerebrum (Fig. $2 B$ ), the antiserum recognizes a band present as early as E15 that peaks during the first postnatal week. Of note, the antiserum appears to recognize only the lower half of the $65 \mathrm{kDa}$ protein band, providing evidence for heterogeneity of proteins in this $65 \mathrm{kDa}$ band. (Presumably the upper half of the band represents an unrelated protein, such as the $70 \mathrm{kDa}$ receptor for CNTF (Davis et al., 1991) or non-cross-reacting OBCAM/neurotrimin-related proteins.) In the cerebellum, the antiserum resolves the $65 \mathrm{kDa}$ band into at least three bands of differing intensities that are developmentally regulated (data not shown). The identity of these proteins and their relationship to neurotrimin is not yet known.

Further characterization of neurotrimin expression was carried out by Northern blot analysis. Thirty micrograms of total RNA isolated from different tissues were probed with a partial $3^{\prime}$ terminal fragment of the neurotrimin cDNA (as it has the most limited homology to OBCAM). Consistent with the pattern of GPI-anchored protein expression, neurotrimin message is only detectable in the adult nervous system and not in a wide variety of non-neural tissues examined (Fig. 6A). In the brain, two mRNA sizes are apparent, a prominent band at $3.2 \mathrm{~kb}$ and a less

\begin{tabular}{|c|c|c|}
\hline Allele & Size & Strains \\
\hline $\mathrm{a}$ & 5.0 & $\begin{array}{l}\text { AKR/J, O20/A, C57L/J, SWR/J, SJL/J, STS/A, NZB/B1NJ, SM/J } \\
\text { AKXD-3,6,7,10,11,13,18,23 } \\
\text { CXJ-6 } \\
\text { CXS-2,3,4,9,10,11,12 }\end{array}$ \\
\hline b & 3.4 & $\begin{array}{l}\text { C57BL/6J, DBA/2J, C3H/HeJ, BALB/cJ } \\
\text { AKXD-1,2,9,14,15,16,20,21,22,24,27 } \\
\text { BXJ- } 1,2 \\
\text { CXJ-1,3,4,8,9,15 } \\
\text { CXS- } 1,5,6,7,8,13,14 \\
\text { LXB-3,4 }\end{array}$ \\
\hline
\end{tabular}

${ }^{a}$ Variant DNA fragments (sizes in kb) were identified in Southern blots of EcoRI-digested genomic DNA. In addition to the variant fragment, DNA from all strains tested also yielded fragments of $9.6,4.0$, and $2.6 \mathrm{~kb}$. 
A

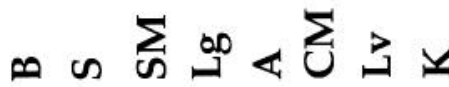
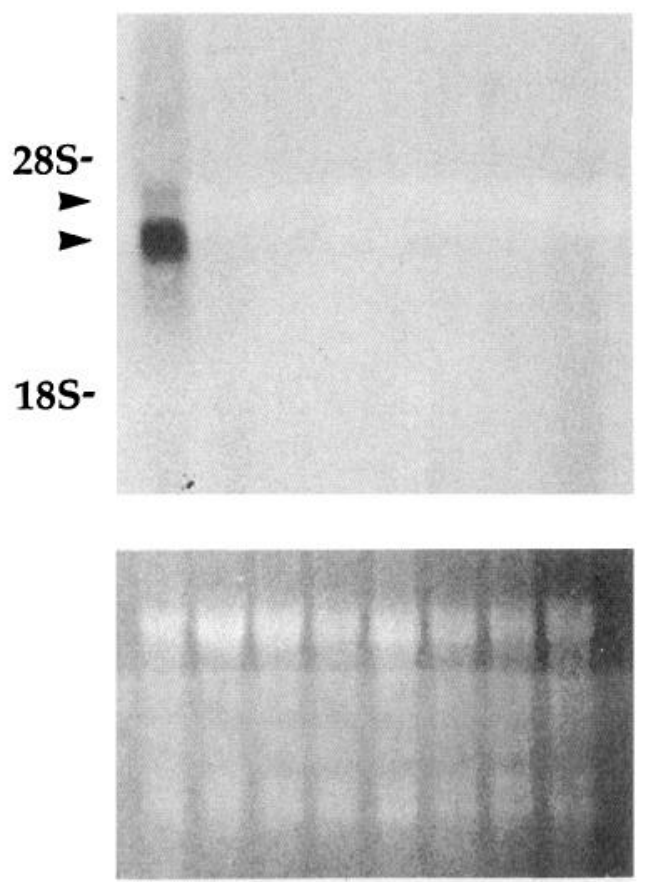

B
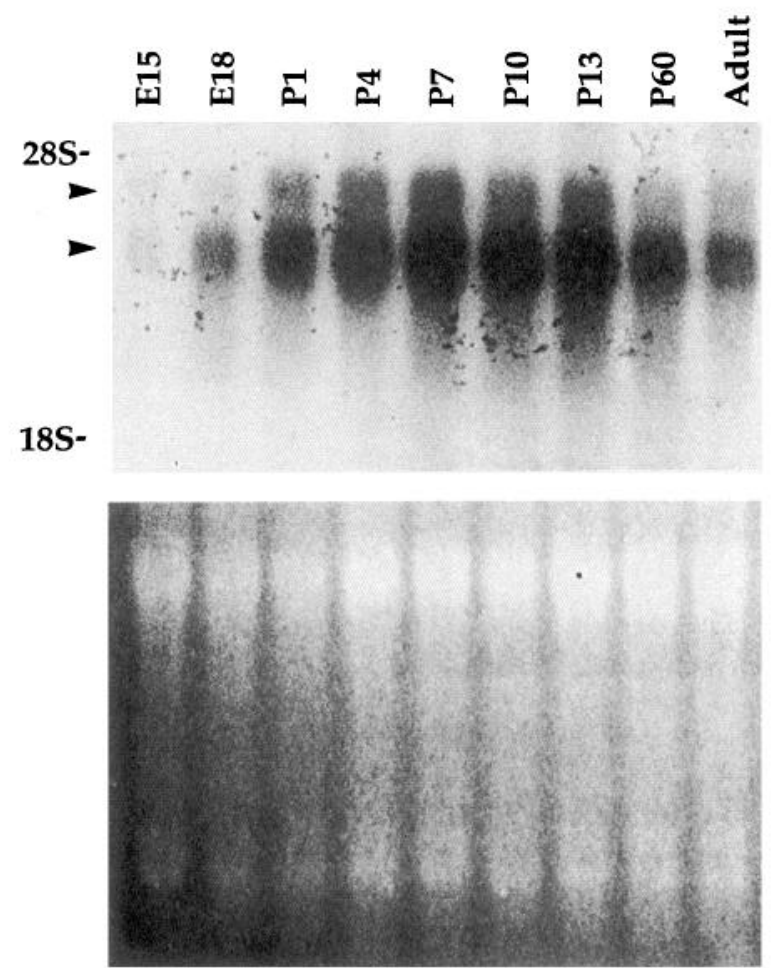

Figure 6. Northern analysis of neurotrimin expression. A, Tissue distribution of neurotrimin mRNA: $30 \mu \mathrm{g}$ of total cellular RNA prepared from brain $(B)$, spleen $(S)$, skeletal muscle $(S M)$, lung $(L g)$, adrenal gland $(A)$, cardiac muscle $(C M)$, liver $(L v)$, and kidney $(K)$ from an adult rat $($ indicated at top) were electrophoresed in a denaturing agarose gel, blotted as described (Sambrook et al., 1989), and probed with a neurotrimin cDNA fragment. The corresponding ethidium bromide stained gel is shown prior to blotting. Neurotrimin message is detectable only in the brain. Two mRNA species are seen (arrowheads): a predominant lower species migrating at about $3.2 \mathrm{~kb}$, and a less abundant species migrating around 4.0 $\mathrm{kb}$. The position of the $18 \mathrm{~S}$ and $28 \mathrm{~S}$ rRNA bands are indicated at the left. $B$, Developmental expression of neurotrimin in the CNS: $30 \mu \mathrm{g}$ of total cellular RNA prepared from rat forebrains of different embryonic $(E)$ or postnatal $(P)$ ages (indicated at top) was electrophoresed in a denaturing agarose gel, blotted, and hybridized with a neurotrimin cDNA probe. The corresponding ethidium bromide stained gel is also shown. Neurotrimin message is detectable by E15, peaks in the first week postnatally, and declines thereafter. The relative intensity of the two bands is constant through development.

intense band at $4.0 \mathrm{~kb}$ (arrowheads, Fig. 6A). As described below, two oligomers complementary to unique and widely spaced sequences of neurotrimin mRNA hybridize to the same two mRNA species strongly suggesting that they represent isoforms of neurotrimin message, rather than mRNAs of related proteins. To determine the developmental pattern of neurotrimin mRNA expression, total RNA was isolated from the forebrains of rats of different ages and probed with the neurotrimin cDNA (Fig. $6 B)$. Both isoforms of neurotrimin message are detectable at $\mathrm{E} 15$, the earliest time point examined, rise gradually prenatally, and peak during the first and second postnatal week. Thereafter, neurotrimin message levels gradually decline to about half maximal levels in the adult, as determined by densitometry (data not shown). The relative intensity of both message isoforms remains constant at all ages studied.

\section{In situ analysis of neurotrimin mRNA expression}

To more precisely characterize the expression pattern of neurotrimin within the developing CNS, we performed in situ analysis using oligonucleotides complementary to unique sequences of neurotrimin mRNA. Both probes recognized the 3.2 and $4.0 \mathrm{~kb}$ neurotrimin mRNA species on Northern blots (data not shown) and yielded identical in situ hybridization labeling patterns that could be specifically blocked with an excess of unlabeled oligonucleotide probe. During embryonic development, at E16 (data not shown) and E18 (Fig. 7), neurotrimin expression appears to be restricted to the nervous system and is expressed in much of the developing gray matter. Specifically, a strong signal is seen in the spinal cord, dorsal root ganglia, and forebrain (Fig. $7 A$ ). On coronal sections (Fig. 7B), intense expression is seen in the developing thalamic nuclei, cortical plate (which corresponds principally to laminae IV-VI at this age), and the retina. Neurotrimin message may also be present in the cortical subplate, although it was difficult to ascertain the demarcation between subplate and cortical plate on these sections. On emulsion-dipped sections of the retina, the hybridization signal is intense over the ganglion cell layer located at the vitreal surface and absent over the mitotic cells of the neuroepithelium located at the choroidal surface (data not shown). Little hybridization signal overlies mitotic cells within the ventricular zone or within the white matter tracts suggesting that expression is restricted to post mitotic neurons. 

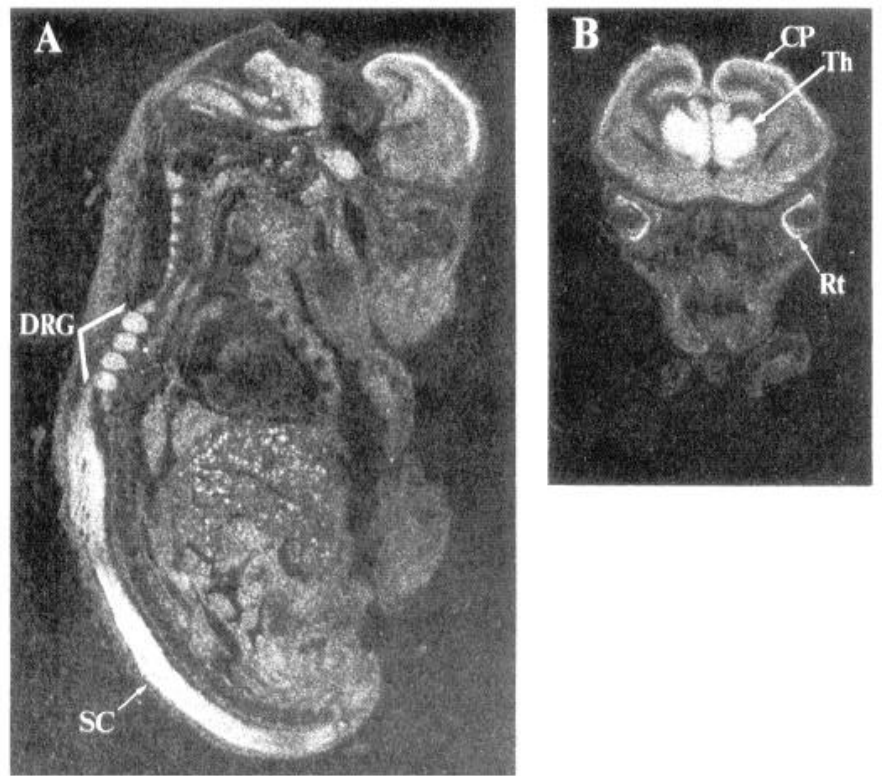

Figure 7. Neurotrimin expression in the E18 CNS. Autoradiographs of in situ hybridization of a parasagittal section $(A)$ and a coronal section $(B)$ of an E18 embryo with a neurotrimin-specific probe, showing distribution of neurotrimin transcripts in the spinal cord $(S C)$, dorsal root ganglia $(D R G)$, and cortical plate in $A$, and cortical plate $(C P)$, thalamus $(T h)$, and retina $(R t)$ in $B$.

As development proceeds, neurotrimin is differentially expressed in specific regions of the CNS, as demonstrated in the series of autoradiographs shown in Figure 8. Regions expressing high levels of neurotrimin message at $\mathrm{P} 0$ include the olfactory bulb, pyriform cortex, midbrain, thalamus, hypothalamus, hippocampus, basal ganglia, and cortical plate. At P7, neurotrimin expression is maintained at high levels, although some diminution of signal may be noted in some regions, particularly the thalamus and striatum. By P14, and at later stages (see Fig. 10) including the adult (not shown), neurotrimin expression is significantly reduced in most regions of the cerebrum. Although present at reduced levels, the pattern of neurotrimin expression within the cortex, thalamus, olfactory bulb, and basal ganglia in general resembles that seen during the first and second postnatal weeks. One exception to the general decline in expression in the CNS occurs in the cerebellum where expression increases substantially beginning at about P10, with significant neurotrimin mRNA apparent over the internal granule cell layer by P14. On emulsion-dipped sections, both granule cells and Purkinje cells were found to express neurotrimin mRNA (data not shown).

Emulsion-dipped sections demonstrated that specific populations of neurons in many of the labeled structures identified on the autoradiographs, expressed neurotrimin mRNA. In the hippocampus, pyramidal neurons within the $\mathrm{CAl}, 2$, and 3 regions express moderate levels of message between P0 and P4; by P14, neurotrimin message continues to be expressed only within CA1 (and at reduced levels) and is absent from CA3 altogether; granule cells of the dentate gyrus do not express neurotrimin to a significant degree at any stage. Similarly, neurons of the habenula express neurotrimin at E18 but by P4 have ceased expression, whereas neurons present in the closely apposed medial thalamus, and in all other thalamic nuclei, continue to express high levels of neurotrimin mRNA at this stage. Within the brainstem, the pontine nucleus shows a strong hybridization signal at
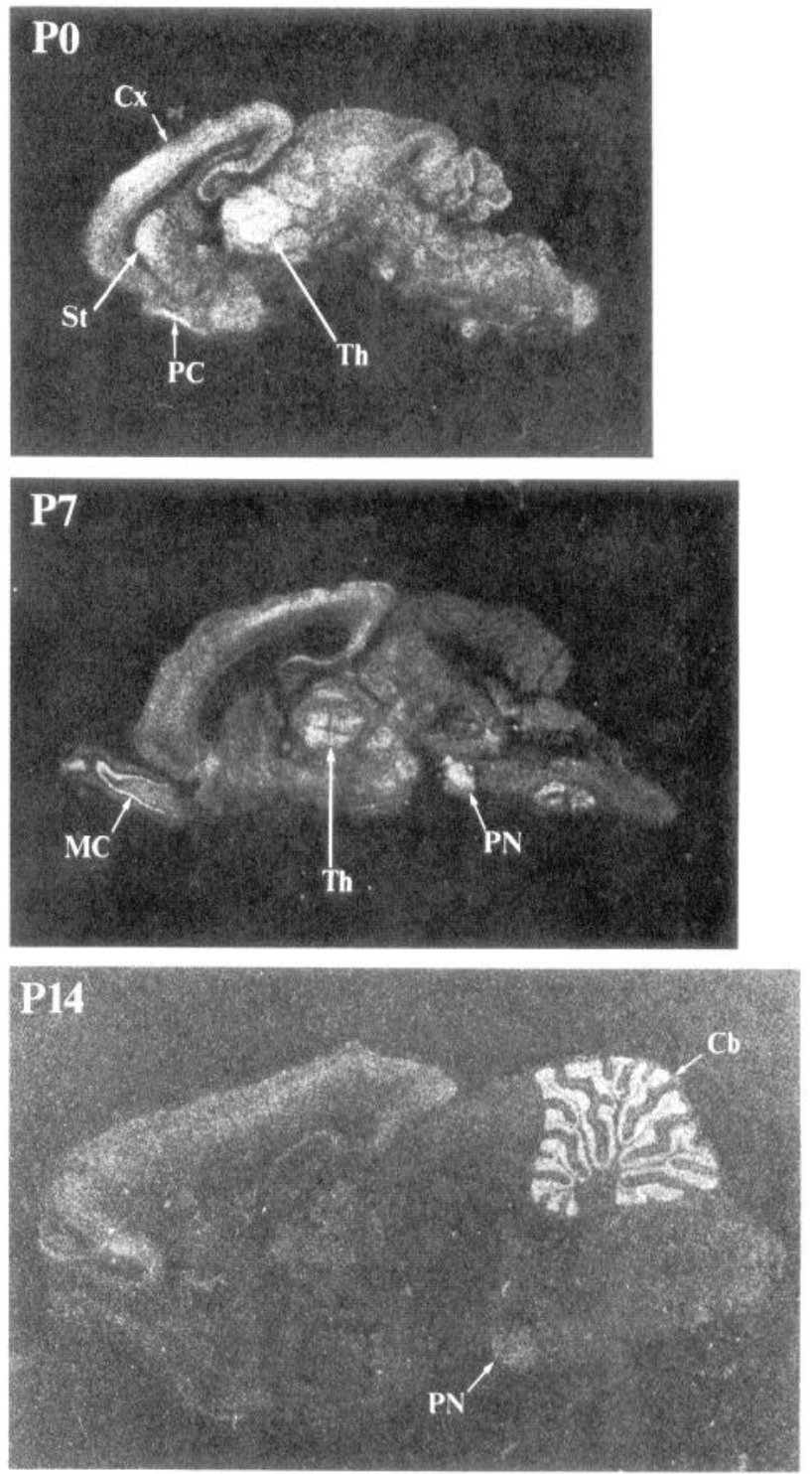

Figure 8. Neurotrimin expression in the developing CNS. Autoradiographs of sagittal sections from P0, P7, and P14 brains hybridized with neurotrimin specific oligonucleotides are shown. The parasagittal section from $\mathrm{PO}$ demonstrates expression in most of the gray matter with particularly high levels of expression in the cortex $(C x)$, pyriform cortex $(P C)$, striatum $(S t)$, and thalamus $(T h)$. By P7, overall expression has diminished somewhat, but high level expression is apparent in the mitral cell layer of the olfactory bulb $(M C)$, in the thalamus $(T h)$, in sensory and motor cortex, and in the pontine nucleus $(P N)$. A laminar pattern of hybridization is seen in the cortex. By P14, expression is markedly downregulated in all regions of the forebrain. An intense signal overlies the granule cell layer of the cerebellum $(\mathrm{Cb})$ and the pontine nucleus $(P N)$.

most stages (see Fig. 8), while other brainstem nuclei and deep cerebellar nuclei express much less neurotrimin message.

An interesting hybridization pattern overlies neurons of the developing basal ganglia. In addition to expression by neurons within the globus pallidus and substantia nigra, a graded distribution of signal intensity is present in a topologically oriented fashion within the striatum. In parasagittal sections, the signal is most intense in the rostral, dorsal region, and present at lower levels in the caudal and ventral regions (data not shown). This 

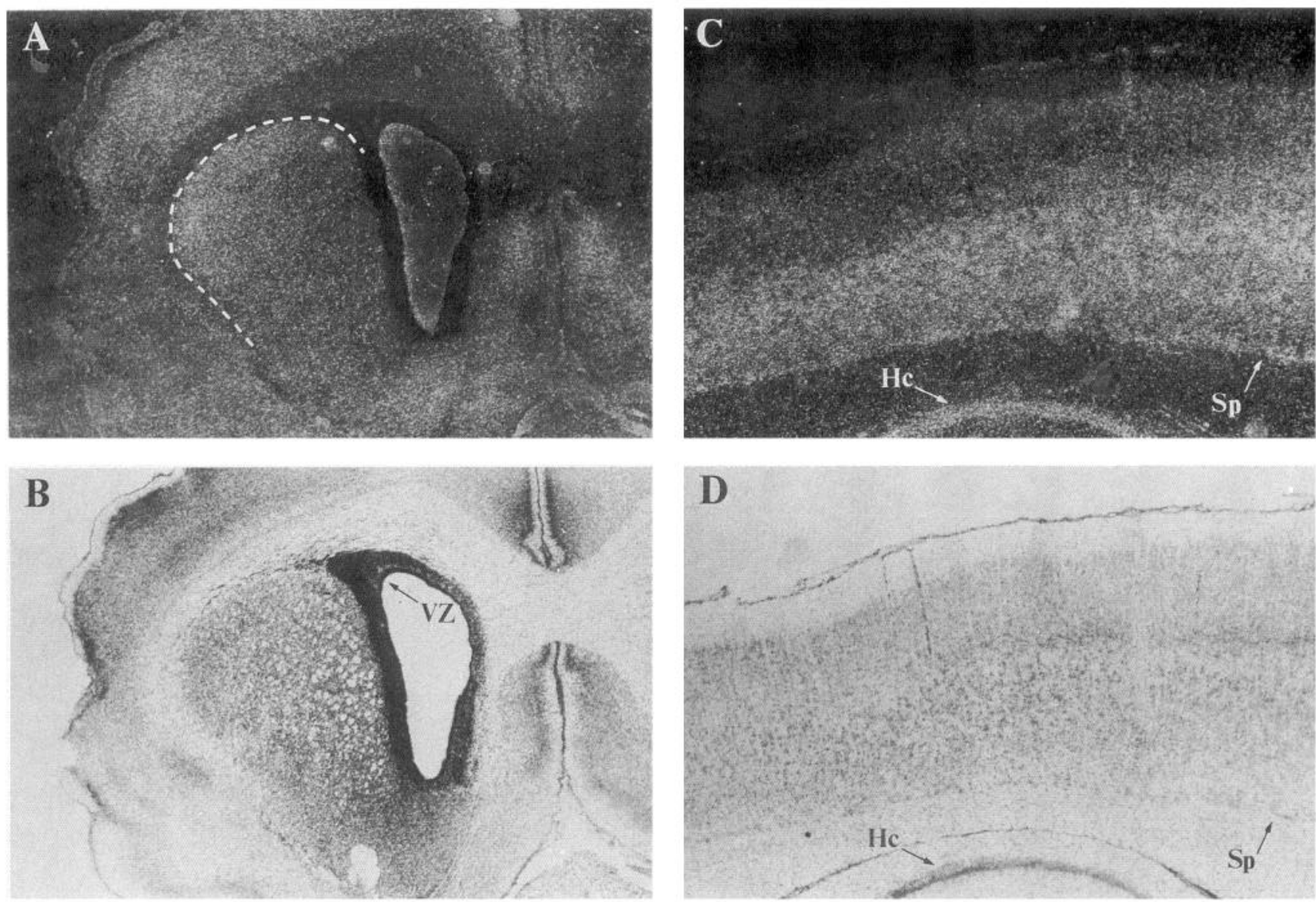

Figure 9. Neurotrimin is differentially expressed within the striatum and cortical laminae. Dark- $(A)$ and bright-field $(B)$ photomicrographs of an in situ hybridization of an anterior coronal section of a P4 rat forebrain with a neurotrimin-specific probe, showing the graded distribution of neurotrimin mRNA transcripts in the striatum (outlined with the dotted white line). Higher signal intensity is seen overlying the dorsolateral striatum. Also of note, the ventricular zone $(V Z)$ does not express neurotrimin message. Neurotrimin also demonstrates a laminar expression pattern in the cerebral cortex $(C$ and $D)$. Dark- $(C)$ and bright-field $(D)$ photomicrographs of a parasagittal section through the P7 parietal cortex hybridized with a neurotrimin-specific probe, demonstrate that cells in laminae V, VI express neurotrimin at the highest levels; cells in lamina I do not express any neurotrimin. Neurons in the hippocampus $(H c)$ and subplate $(S p)$ also express neurotrimin at high levels ( $A$ also demonstrates subplate labeling).

higher intensity signal is readily apparent in the rostral dorsolateral striatum on anterior coronal sections (Fig. 9A).

Finally, a laminar pattern of expression was visible within the olfactory bulb and cerebral cortex. Within the olfactory bulb, intense hybridization signal was present over the mitral cell layer, which receives its major input from the olfactory cortex. Olfactory neurons were not labeled and the other layers of the bulb, i.e., the glomeruli, the external plexiform layer, the internal plexiform, and the granule cells, were only lightly or moderately labeled. This pattern of expression is maintained at most developmental stages (data not shown). In the cerebral cortex, laminae $\mathrm{V}$ and VI express the highest levels of neurotrimin at P0 to P4, although all layers except the outer plexiform layer (lamina I) show some expression. At P7 the laminar distribution is more marked than at earlier ages, with the highest levels of expression in laminae V and VI, as well as in the subplate (Fig. 9C). Expression within the hippocampus is also apparent on this section. No clear demarcation into radially organized domains was observed at different developmental stages, although there appears to be higher expression in sensorimotor compared to entorhinal cortex (see Fig. 10A). The implications of these findings are considered further in the discussion.

\section{Neurotrimin and OBCAM are expressed in distinct regions of the developing CNS}

As a further check of the specificity of the neurotrimin hybridization pattern and to determine the pattern of expression of a highly related family member, oligonucleotides complementary to OBCAM sequences were also characterized by in situ hybridization (Fig. 10). Like neurotrimin, OBCAM expression is limited to gray matter and maximal in the first postnatal week, suggesting that it is restricted to postmitotic neurons. However, OBCAM is expressed in a more restricted set of neurons than is neurotrimin, with high levels of expression principally within the hippocampus and mitral cells of the olfactory bulb and moderate levels of expression in the cortical laminae. At E18, OBCAM mRNA is localized to the cortical plate, and possibly the subplate and spinal cord at low levels (data not shown). In contrast to neurotrimin, little signal is present in the developing thalamus or dorsal root ganglia. During the first postnatal week, OBCAM is prominent within cerebral cortex, developing hippocampus, pyriform cortex, and the mitral cell layer of the olfactory bulb (Fig. 10D). Within the hippocampus, a strong hybridization signal is seen overlying all regions of Ammon's horn, 

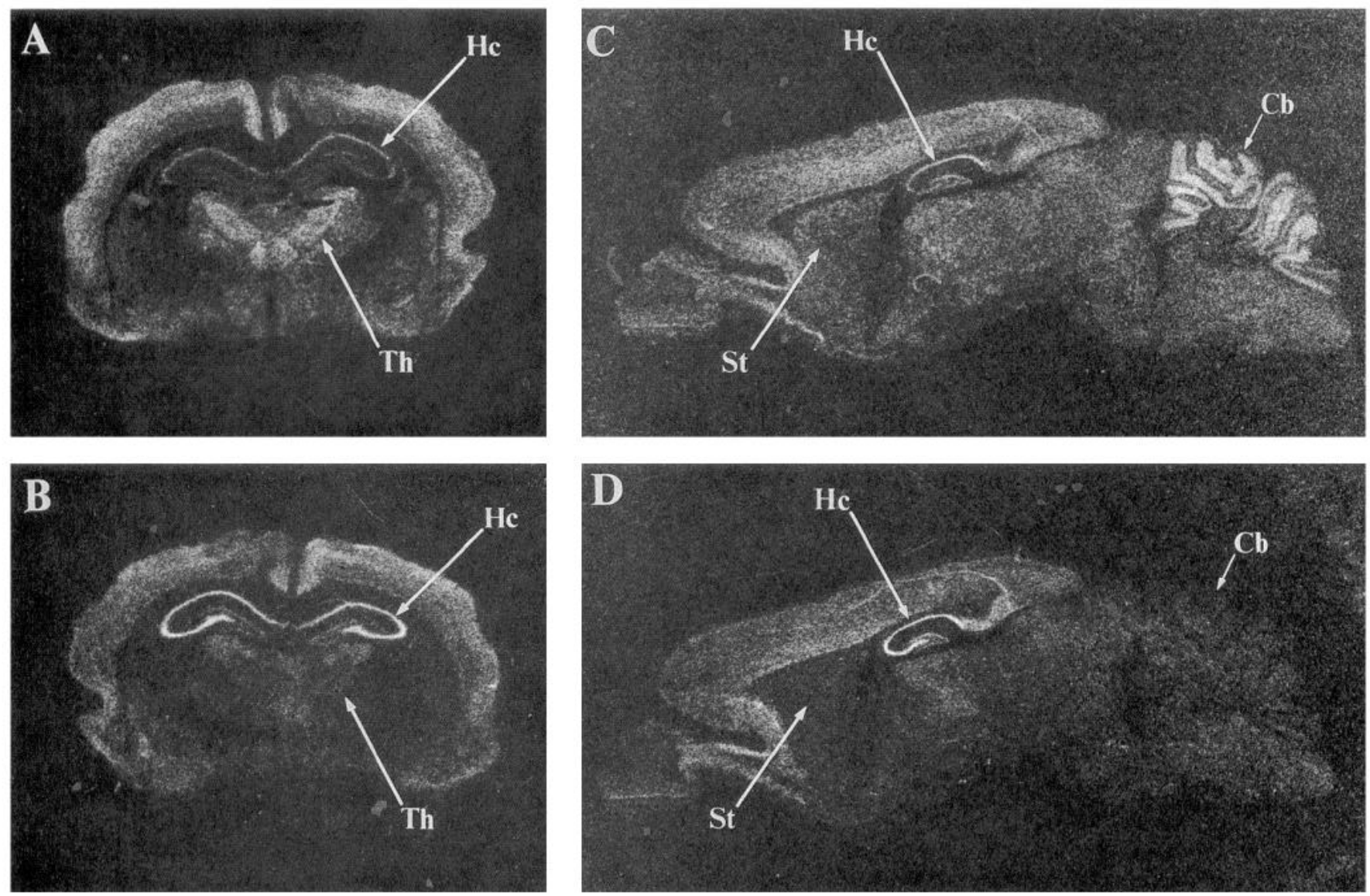

Figure 10. Neurotrimin and OBCAM are expressed in different regions of the developing rat CNS. Autoradiographs of in situ hybridizations with a neurotrimin specific probe $(A$ and $C)$ and an OBCAM specific probe $(B$ and $D)$ are shown. Serial coronal sections through the P7 rat cerebrum were hybridized in $A$ and $B$ and serial parasagittal sections of the P20 CNS in $C$ and $D$. On the coronal sections, OBCAM expression (B) is more restricted than neurotrimin $(A)$, with strong expression in CA1, 2, and 3 of the hippocampus $(H c)$, moderate expression in the cerebral cortex, and minimal expression in the thalamus (Th); no OBCAM mRNA was detected overlying the basal ganglia. On the parasagittal sections, OBCAM mRNA $(D)$ was present at high levels in the hippocampus, at moderate levels in the cerebral cortex, olfactory bulb, pyriform cortex, and very weakly in portions of the thalamus. No OBCAM is detectable in the brainstem, striatum $(\mathrm{St})$, or cerebellum $(\mathrm{Cb})$, in striking contrast to the distribution of neurotrimin message (shown in $C$ ).

with much lower signal overlying the dentate gyrus (Fig. 10B). The cortical plate also displays strong labeling with a differential laminar distribution. In contrast to neurotrimin (Fig 10A), there is very limited expression, if any, within most of the thalamic nuclei. Also, in contrast to neurotrimin, very low levels of OBCAM message expression were observed in the brainstem, cerebellum, and no expression was detected in the basal ganglia at this stage or at P20 (Fig. 10D).

\section{Discussion}

We have surveyed the expression of GPI-anchored proteins in the developing rat brain in an effort to identify a broadly migrating $65 \mathrm{kDa}$ protein band that we previously found to differentially expressed by primary neurons (Rosen et al., 1992). This protein band is restricted to the nervous system and is the most abundant and the earliest expressed of the GPI-anchored species in the CNS. We have determined that it is comprised of a family of IgSF members, each containing three Ig-like domains that share significant amino acid identity. One of these proteins is OBCAM (Schofield et al., 1989). We have isolated and sequenced a cDNA encoding a second member of this family that we have termed neurotrimin, and present evidence for the ex- istence of additional family members. Differential expression of neurotrimin and OBCAM suggests they, together with other members of this family, may have a role in generating diversity of the neuronal cell surface during development. These findings are considered in more detail below.

Neurotrimin expression appears to be restricted to postmitotic neurons. By Northern and Western blots, neurotrimin is first expressed on or before E15 in the forebrain and peaks during the first postnatal week (its expression peaks somewhat later in the cerebellum). This early and abundant expression in the cerebral cortex corresponds to a period when the majority of cortical neurons have been generated and precedes the period of maximal gliogenesis (Paterson et al., 1973). In addition, by in situ hybridization, no signal was observed over the dividing cells of the ventricular zone or over white matter structures, i.e., the corpus callosum, fornix, internal capsule, and cerebral and cerebellar molecular layers. Also, in areas of high message abundance, such as the 1-week-old thalamus, clusters of silver grains representing hybridization signal were clearly observed over neurons but not glia in emulsion dipped sections (data not shown). Finally, the $65 \mathrm{kDa}$ band was not seen in extractions of GPI-anchored proteins from cultured astrocytes or Schwann 
cells in different stages of differentiation (C. Rosen, L. Lovejoy and J. Salzer, unpublished observations), and Schwann cells do not express detectable levels of neurotrimin mRNA (data not shown).

Neurotrimin has a core polypeptide of $39 \mathrm{kDa}$, that is heavily glycosylated, with the mature polypeptide migrating at approximately $65 \mathrm{kDa}$. Two neurotrimin mRNA species, with sizes of 3.2 and $4.0 \mathrm{~kb}$, can be detected by Northern analysis. These classes of neurotrimin message appear to be coordinately regulated, as their relative intensities remain unchanged through development. We think it likely that these represent alternatively spliced variants of untranslated segments of neurotrimin. No alternative isoforms of the protein were seen on the Western blots of GPI-anchored proteins using the anti-neurotrimin antiserum, and seven neurotrimin cDNAs we have characterized all had identical $3^{\prime}$ ends. Interestingly, three alternatively spliced OBCAM cDNAs have been isolated; these differ only in their $5^{\prime}$ noncoding region and, in one case, in part of the signal peptide the sequence (Lippman et al., 1992). Based on the in situ hybridization studies and ease of mRNA detection by Northern blots, neurotrimin appears to be significantly more abundant than OBCAM (Schofield et al., 1989).

\section{Neurotrimin is a member of a new subfamily of the IgSF}

Peptide microsequencing of the $65 \mathrm{kDa}$ band demonstrated that it contained a mixture of at least two proteins, as one peptide is a partial OBCAM peptide and the other a partial neurotrimin peptide. In addition, using the anti-neurotrimin antibody, we have been able to resolve the $65 \mathrm{kDa}$ band into three bands of varying intensities in some instances. Further, using a $73 \mathrm{bp}$ exonic sequence that is conserved between OBCAM and neurotrimin, we have identified up to five distinct genomic segments that are complementary, suggesting that several additional related genes are yet to be identified. We cannot exclude at this time, however, that some of these additional sequences may represent pscudogenes.

Of particular note in this regard, we have recently isolated by degenerate PCR using a rat brain cDNA template, a partial CDNA that is very similar to both OBCAM and neurotrimin ( $O$. Gil, G. Zanazzi, and J. Salzer, unpublished). Concomitantly, we became aware that a cDNA for the limbic associated membrane protein (LAMP), a cell adhesion molecule specific to the limbic system (Keller et al., 1989), had been cloned and was a new GPI-anchored IgSF member (Pimenta et al., 1993). Comparison of the sequence of LAMP with that of the PCR-generated CDNA indicate that they are identical (P. Levitt, personal communication). The full sequence of LAMP is approximately $67 \%$ identical at the nucleotide level, and 54\% identical at the amino acid level to both OBCAM and neurotrimin and is comprised of three C2 domains (P. Levitt, personal communication). Thus LAMP, together with neurotrimin and OBCAM, are members of a new subfamily of Ig-like CAMs. Moreover, it remains quite likely, in view of the genomic Southern blots, that additional members may exist.

This subfamily is characterized by having several common structural elements as well as a significant degree of amino acid sequence homology. Structural similarities include three C2-type immunoglobulin domains, with the first and third being full $\mathrm{C} 2$ domains and the middlc domain being a truncated $\mathrm{C} 2$ domain, and a GPI anchor. All three proteins are extensively glycosylated with six potential $\mathrm{N}$-linked sites in the case of OBCAM and eight in the case of LAMP (Pimenta et al., 1993) and neurotri- min. Neurotrimin and OBCAM are more closely related to each other than either is to LAMP, with particularly striking homology between the first immunoglobulin domains of these two proteins. Within the stretch of 100 residues that comprises this domain, there are only eight amino acid differences between OBCAM and neurotrimin, and five of these are conservative substitutions. Domains two and three of neurotrimin and OBCAM share $70 \%$ and $66 \%$ identity, respectively. The region of nucleotide identity between OBCAM and neurotrimin, particularly in their $5^{\prime}$ regions, is also quite striking, extending from the $5^{\prime}$ untranslated region through the first Ig domain. The extended identity between these two proteins may reflect conservation of an important functional scgment, recent cvolutionary divergence of their respective genes or, possibly, gene conversion. Gene conversion in particular has been proposed as a mechanism to account for the extended identity that exists between the tandemly arrayed members of the immunoglobulin heavy-chain and cytochrome P-450 gene complexes, among others (Yamawaki-Kataoka et al., 1982; Atchison and Adesnik, 1986). Perhaps consistent with recent evolutionary divergence and/or gene conversion in this subfamily, the neurotrimin gene is located immediately proximal to Etsl on mouse chromosome 9, suggesting that it is closely linked to Obcam (Chakraborti et al., 1993) and possibly Icam (Seldin et al., 1991). These findings raise the possibility that these three members of the IgSF may be clustered in the genome. Further physical and genetic mapping studies will be needed to test this hypothesis and to determine whether other members of this family, including LAMP, may be similarly clustered.

While OBCAM, LAMP, and neurotrimin clearly form a distinct subgroup within the IgSF, they also share several important features with two recently characterized invertebrate proteins, amalgam (Seeger et al., 1988) and lachesin (Karlstrom et al., 1993). Notably, both of these proteins contain three Ig-like domains and are GPI-anchored to the cell surface. They are also prominently expressed in the nervous system: lachesin is expressed by all early neuroblasts and by a specific subsets of axons in the mature CNS of the grasshopper (Karlstrom et al., 1993), while amalgam is expressed on very early mesoderm, on neurons and axons in the developing CNS, and later on specific subsets of neuronal cell bodies in the PNS in Drosophila (Seeger et al., 1988). However unlike LAMP, OBCAM, and neurotrimin, the first Ig-like domain of both amalgam and lachesin is a variable-like domain. In addition, these proteins have only a few $\mathrm{N}$-linked carbohydrate attachment sites and exhibit only modest homology to neurotrimin and OBCAM that is not significantly higher than that to several IgSF members that do not function in cell adhesion (i.e., nonmuscle light chain kinase, the $f t$ receptor). In the future, determination of the intron-exon organization of these different genes may help clarify their evolutionary relationship to the neurotrimin-related proteins and to other three Ig domain proteins such as the poliovirus receptor (Mendelsohn et al., 1989) and several members of the CEA superfamily (Khan et al., 1992).

An additional notable feature of these proteins is that they share a GPI-linkage to the plasma membrane. A large proportion of CAMs in the nervous system, such as TAG-1/axonin-1, F3/ F11, an isoform of NCAM, Thy-1, and T-cadherin in vertebrates and fasciclin I in invertebrates, are GPI anchored, and with the description of this novel family of neurotrimin-like proteins, that proportion is growing. The reason why so many neural CAMs are GPI-anchored to the membrane is not known. A number of 
potential advantages for their function in cell adhesion have been suggested (see Salzer et al., in press, for a recent review). These include enhanced planar mobility (Ishihara et al., 1987; Noda et al., 1987) that could serve to promote adhesion by recruitment of these proteins into sites of cell contact (Chan et al., 1991), targeting these proteins to specific membrane domains including axons (Lisanti et al., 1988; Dotti et al., 1991), cleavage, and release from the plasma membrane by anchor-specific phospholipases (Metz et al., 1994), which might provide a mechanism for regulating adhesive events (Stoeckli et al., 1991), and participation in signal transduction through activation of intracellular second-messenger systems (Stefanová et al., 1991; Su et al., 1991). Whether any of these features are relevant to the function of neurotrimin will require further investigation.

\section{Homology of neurotrimin to other proteins}

As described earlier, neurotrimin demonstrates striking homology to OBCAM, very high homology to LAMP, and significant homology to a number of well-characterized neural cell adhesion molecules including NCAM, MAG, and axonin-1 among others (see Table 1). OBCAM was originally isolated as a potential mu-type opiate receptor (Cho et al., 1986). However, subsequent studies have shown that the physiologic opiate receptors belong to the G-protein-coupled receptor family (Evans et al., 1992; Kiefer et al., 1992). Indeed, OBCAM does not promote direct binding of opioids when transfected into heterologous cells (Loh and Smith, 1990), although it has been suggested that it may have an indirect role in opiate binding and signaling (Govitrapong et al., 1993). Similarly, in preliminary studies in which we have transfected neurotrimin into a $\mathrm{CHO}$ cell line, we have not detected any increase in the binding of an opioid agonist (A. F. Struyk, E. Simon, and J. Salzer, unpublished observations). Rather we favor the notion that neurotrimin and OBCAM, like LAMP and the other neural CAMs (to which all three proteins are homologous), have a role in mediating cell interactions in the nervous system.

The role of LAMP during neural development has been extensively characterized by P. Levitt and his colleagues. LAMP is a 64-68 kDa GPI-anchored glycoprotein with a core polypeptide size of $37 \mathrm{kDa}$ (Zacco et al., 1990). It is expressed by neurons in the limbic system or associated structures including the hippocampus, some nuclei of the thalamus, in the entorhinal cortex and the molecular layer of the cerebellum (Levitt, 1984); its expression begins about E14-15 in the rat (Zacco et al., 1990). A number of studies have suggested that LAMP expression correlates with the acquisition of a stable identity by limbic system neurons and may be important in their pathfinding and synaptic target recognition (Keller ct al., 1989; Barbc and Levitt, 1991). For example, in vitro, anti-LAMP antibodies block the ability of septal neurons to extend fibers into hippocampal tissue sections or synapse appropriately (Keller et al., 1989). Substratebound LAMP has been reported to specifically promote attachment and nerve fiber outgrowth by perirhinal limbic cortical neurons but not by other nonlimbic neurons (Zhukareva and Levitt, 1993). Taken together, these observations suggest that LAMP may function as a limbic system specific CAM to promote appropriate pathfinding and target recognition during development.

Potential significance of the pattern of neurotrimin expression during development

The high homology of LAMP with neurotrimin and OBCAM raises the possibility that these latter proteins could similarly promote system specific development in vivo. While widespread, the expression of neurotrimin does appear to correlate with the development of several neural circuits. For example, between E18 and P10, neurotrimin mRNA expression within the forebrain is maintained at high levels in neurons of the developing thalamus, cortical subplate, and cortex, particularly laminae V and VI (with less intense expression in II, III, and IV, and minimal expression in lamina I). It is of interest in this regard that cortical subplate neurons may provide an early, temporary scaffold for the ingrowing thalamic afferents en route to their final synaptic targets in the cortex (see Allendoerfer and Shatz, 1994, for a recent review). Conversely, subplate neurons have been suggested to be required for cortical neurons from layer VI to grow into the thalamus, and neurons from layer $\mathrm{V}$ to select their targets in the colliculus, pons, and spinal cord (McConnell et al., 1994). Essentially nothing is known about the molecular basis by which these projections are established, although membrane-bound factors are believed to be involved (Bolz et al., 1993). The high level expression of neurotrimin in many of these sites suggests that it could be involved in the development of these projections.

Similarly, in the hindbrain, high levels of neurotrimin message expression were observed within the pontine nucleus and by the internal granule cells and Purkinje cells of the cerebellum. The pontine nucleus receives afferent input from a variety of sources including corticopontine fibers of layer $\mathrm{V}$, and is a major source of afferent input, via mossy fibers, to the granule cells which, in turn, are a major source of afferent input via parallel fibers to Purkinje cells (Palay and Chan-Palay, 1974). High level expression of neurotrimin in these neurons again suggests potential involvement in the establishment of these circuits.

Of additional interest is the graded pattern of neurotrimin in the early postnatal striatum. Increased neurotrimin expression is found overlying the dorsolateral striatum (Fig. 10), while lesser hybridization intensity is seen overlying the ventromedial striatum. This region of higher neurotrimin hybridization intensity does not correspond to a cytoarchitecturally differentiable region; rather, it corresponds to the primary area of afferent input from layer VI of the contralateral sensorimotor cortex (Jones et al., 1977; Gerfen, 1984; Donoghue and Herkenham, 1986). The ventromedial striatum, by contrast, receives the majority of its afferent input from the perirhinal and association cortex (Gerfen, 1984; Donoghue and Herkenham, 1986). It is interesting to note that a complementary graded pattern of LAMP expression, both protein (Levitt, 1984; Chesselet et al., 1991) and message (P. Levitt, personal communication) has been observed within the striatum, with highest expression in ventromedial regions, and lowest expression dorsolaterally. Thus, within the striatum, which is comprised of a histologically uniform population of medium spiny neurons, two members of this subfamily of proteins are differentially expressed in a complementary, graded fashion that directly corresponds to topographically defined regions of afferent input. Interestingly, other areas of high neurotrimin expression, i.e., the pontine nucleus, Purkinje and internal granule cells of the cerebellum, sensorimotor and pyriform cortex, and the olfactory bulb, are areas with low expression of LAMP (Levitt, 1984), whereas LAMP is expressed at high levels in several structures (the amygdala, entorhinal cortex, and a number of brainstem nuclci) where ncurotrimin is expressed at low levels.

Comparison of the pattern of neurotrimin and OBCAM expression reveals that these two very homologous proteins are 
also distinctly distributed. The most abundant OBCAM expression was observed in the hippocampus, where it is expressed at very high levels within CA1, 2, and 3, at lesser levels within the presubiculum and subiculum, and not at all within the dentate gyrus. This pattern of expression overlaps with neurotrimin, which demonstrates more moderate expression within Ammon's horn and greater expression over the subiculum during the first postnatal week, before undergoing significant downregulation by P14. At later ages, OBCAM is expressed prominently within all regions of Ammon's horn, whereas neurotrimin expression is absent within $2 / 3$, and significantly downregulated within CAl. Neurotrimin and OBCAM message expression also overlap within the developing cortical plate, but they may have different laminar distributions. OBCAM and neurotrimin are also coexpressed in the mitral cell layer of the olfactory bulb and the pyriform cortex. OBCAM is not expressed in some cell populations in which neurotrimin is found in abundance, including the early postnatal retina, thalamus, striatum, and, at later ages, the cerebellum. These results further support the notion that neurons in different regions of the CNS express different combinations of this family of proteins during development.

Taken together, the distinct distribution and differential relative expression of neurotrimin, OBCAM, and LAMP, suggests that they may contribute to the diversity at the surface of different populations of neurons during development. Future studies focused on characterizing the pattern of protein expression, including whether they are coexpressed by individual neurons; identification of other potential family members; and modification of their expression in vivo by molecular genetic strategies should help clarify the role of this family of proteins in the specification of neural projections.

\section{References}

Allendoerfer KL, Shatz CJ (1994) The subplate, a transient neocortical structure: its role in the development of connections between thalamus and cortex. Annu Rev Neurosci 17:185-218.

Atchison M, Adesnik M (1986) Gene conversion in a cytochrome P-450 gene family. Proc Natl Acad Sci USA 83:2300-2304.

Barbe MF, Levitt $P$ (1991) The early commitment of fetal neurons to the limbic cortex. J Neurosci 11:519-533.

Barthels D, Santoni NJ, Wille W, Ruppert C, Chaix JC, Hirsch MR, Fontecilla CJC, Goridis C (1987) Isolation and nucleotide sequence of mouse NCAM cDNA that codes for a $M_{r} 79,000$ polypeptide without a membrane-spanning region. EMBO J 6:907-914 [published erratum, 6:3202].

Blank RD, Campbell GR, Calabro A, D'Eustachio P (1998) A linkage map of mouse chromosome 12: localization of $I g h$ and effects of sex and interference on recombination. Genetics 120:1073-1083.

Bolz J, Götz M, Hübner M, Novak N (1993) Reconstructing cortical connections in a dish. Trends Neurosci 16:310-316.

Brümmendorf T, Rathjen FG (1993) Axonal glycoproteins with immunoglobulin- and fibronectin type III-related domains in vertebrates: structural features, binding activities, and signal transduction. J Neurochem 61:1207-1219.

Burgoon MP, Grumet M, Mauro V, Edelman GM, Cunningham BA (1991) Structure of the chicken neuron-glia cell adhesion molecule, $\mathrm{Ng}$-CAM: origin of the polypeptides and relation to the Ig superfamily. J Cell Biol 112:1017-1029.

Chakraborti A, Lippman DL, Loh HH, Kozak CA, Lee NM (1993) Genetic mapping of opioid binding protein gene(s) to mouse chromosome 9. Mammal Genome 4:179-182.

Chan PY, Lawrence MB, Dustin ML, Ferguson LM, Golan DE, Springer TA (1991) Influence of receptor lateral mobility on adhesion strengthening between membranes containing LFA-3 and CD2. J Cell Biol 115:245-255.

Chang WS, Serikawa K, Allen K, Bentley D (1992) Disruption of pioneer growth cone guidance in vivo by removal of glycosylphos- phatidylinositol-anchored cell surface proteins. Development 114 : 507-519.

Chesselet M-F, Gonzales C, Levitt P (1991) Heterogeneous distribution of the limbic system-associated membrane protein in the caudate nucleus and substantia nigra of the cat. Neuroscience 40:725-733.

Cho TM, Hasegawa J-I, Ge BL, Lu HH (1986) Purification to apparent homogeneity of a $\mu$-type opioid receptor from rat brain. Proc Natl Acad Sci USA 83:4138-4142.

Davis S, Aldrich TH, Valenzuela DM, Wong VV, Furth ME, Squinto SP, Yancopoulos GD (1991) The receptor for ciliary neurotrophic factor. Science 253:59-63.

Dodd J, Morton SB, Karagogeos D, Yamamoto M, Jessell TM (1988) Spatial regulation of axonal glycoprotein expression on subsets of embryonic spinal neurons. Neuron 1:105-116.

Doherty P, Walsh FS (1992) Cell adhesion molecules, second messengers and axonal growth. Curr Opin Neurobiol 2:595-601.

Donoghue JP, Herkenham M (1986) Neostriatal projections from individual cortical fields conform to histochemically distinct striatal compartments in the rat. Brain Res. 365:397-403.

Dotti CG, Parton RG, Simons K (1991) Polarized sorting of glypiated proteins in hippocampal neurons. Nature 349:158-161.

Edelman GM, Crossin KL (1991) Cell adhesion molecules: implications for a molecular histology. Annu Rev Biochem 60:155-190.

Evans CJ, Keith JDE, Morrison H, Magendzo K, Edwards RH (1992) Cloning of a delta opioid receptor by functional expression. Science 258:1952-1955.

Furley AJ, Morton SB, Manalo D, Karagogeos D, Dodd J, Jessell TM (1990) The axonal glycoprotein TAG-1 is an immunoglobulin superfamily member with neurite outgrowth-promoting activity. Cell $61: 157-170$.

Gennarini G, Cibelli G, Rougon G, Mattei M-G, Goridis C (1989a) The mouse neuronal cell surface protein F3: a phosphatidylinositolanchored member of the immunoglobulin superfamily related to chicken contactin. J Cell Biol 109:775-778.

Gennarini G, Rougon G, Vitiello F, Corsi P, Di BC, Goridis C (1989b) Identification and CDNA cloning of a new member of the L2/HNK-1 family of neural surface glycoproteins. J Neurosci Res 22:1-12.

Gerfen CR (1984) The neo-striatal mosaic: compartmentalization of corticostriatal input and striatonigral output systems. Nature 311:461464.

Goodman CS, Shatz CJ (1993) Developmental mechanisms that generate precise patterns of neuronal connectivity. Cell/Neuron [Suppl] 72/10:77-98.

Govitrapong P, Zhang X, Loh HH, Lee NM (1993) Transfection of NG108-15 cells with antisense opioid-binding cell adhesion molecule cDNA alters opioid receptor-G-protein interaction. J Biol Chem 268: 18280-18285.

Grenningloh G, Rehm EJ, Goodman CS (1991) Genetic analysis of growth cone guidance in Drosophila: fasciclin II functions as a neuronal recognition molecule. Cell 67:45-57.

Hasler TH, Rader C, Stoeckli ET, Zuellig RA, Sondregger P (1993) cDNA cloning, structural features, and eucaryotic expression of human TAG-1/axonin-1. Eur J Biochem 211:329-339.

He HT, Barbet J, Chaix JC, Goridis C (1986) Phosphatidylinositol is involved in the membrane attachment of NCAM-120, the smallest component of the neural cell adhesion molecule. EMBO J 5:2489 2494.

Heijne Gv (1986) A new method for predicting signal sequence cleavage sites. Nucleic Acids Res 14:4683-4691.

Hortsch M, Goodman CS (1990) Drosophila fasciclin I, a neural cell adhesion molecule, has a phosphatidylinositol lipid membrane anchor that is developmentally regulated. J Biol Chem 265:15104 15109.

Ishihara A, Hou Y, Jacobson K (1987) The Thy-1 antigen exhibits rapid lateral diffusion in the plasma membrane of rodent lymphoid cells and fibrublasts. Proc Natl Acad Sci USA 84:1290-1293.

Jessel TM (1988) Adhesion molecules and the hierarchy of neural development. Neuron 1:3-13.

Jones EG, Coulter JD, Burton H, Porter R (1977) Cells of origin and terminal distribution of corticostriatal fibers arising in the sensorymotor cortex of monkeys. J Comp Neurol 173:53-80.

Karlstrom RO, Wilder LP, Bastiani MJ (1993) Lachesin: an immunoglobulin superfamily protein whose expression correlates with neurogenesis in grasshopper cmbryos. Dcvelopment 118:509-522.

Keller F, Rimvall K, Barbe M, Levitt P (1989) A membrane glycopro- 
tein associated with the limbic system mediates the formation of the septo-hippocampal pathway in vitro. Neuron 3:455-474.

Khan WN, Teglund S, Bremer K, Hammarström S (1992) The pregnancy-specific glycoprotein family of the immunoglobulin superfamily: identification of new members and estimation of family size. Genomics 12:780-787.

Kiefer BL, Bcfort K, Gaveriaux-Ruff C, Hirth CG (1992) The d-opioid receptor: isolation of a CDNA by expression cloning and pharmacological characterization. Proc Natl Acad Sci USA 89:12048-12052.

Kodukula K, Gerber LD, Amthauer R, Brink L, Udenfriend S (1993) Biosynthesis of glycosylphosphatidylinositol (GPI)-anchored membrane proteins in intact cells: specific amino acid requirements adjacent to the site of cleavage and GPI attachment. J Cell Biol 120: $657-664$

Laemmli UK (1970) Cleavage of structural proteins during the assembly of the head of bacteriophage T4. Nature 227:680-685.

Levitt P (1984) A monoclonal antibody to limbic system neurons. Science 223:299-301.

Levy JB, Canoll PD, Silvennoinen O, Barnea G, Morse B, Honegger AM, Huang J-T, Cannizzaro LA, Park S-H, Druck Y, Huebner K, Sap J, Ehrlich M, Musacchio JM, Schlessinger J (1993) The cloning of a receptor-type protein tyrosine phosphatase expressed in the central nervous system. J Biol Chem 268:10573-10581.

Lipman DJ, Pearson WR (1985) Rapid and sensitive protein similarity searches. Science 227:1435-1440.

Lippman DA, Lee NM, Loh, HH (1992) Opioid-binding cell adhesion molecule (OBCAM)-related clones from a rat brain cDNA library. Gene 117:249-254

Lisanti MP, Sargiacomo M, Graeve L, Saltiel AR, Rodriguez-Boulan E (1988) Polarized apical distribution of glycosylphosphatidylinositolanchored proteins in a renal epithelial cell line. Proc Natl Acad Sci USA 85:9557-9561.

Loh HH, Smith AP (1990) Molecular characterization of opioid receptors. Annu Rev Pharmacol Toxicol 30:123-147.

Mayford M, Barzilai A, Keller F, Schacher S, Kandel ER (1992) Modulation of an NCAM-related adhesion molecule with long-term synaptic plasticity in Aplysia. Science 256:638-644.

McConnell SK, Ghosh A, Shatz CJ (1994) Subplate pioneers and the formation of descending connections from cerebral cortex. J Neurosci 14:1892-1907.

Mendelsohn CL, Wimmer E, Racaniello VR (1989) Cellular receptor for poliovirus: molecular cloning, nucleotide sequence, and expression of a new member of the immunoglobulin superfamily. Cell 56 : $855-865$.

Metz CN, Brunner G, Choi-Muira NH, Nguyen H, Gabrilove J, Caras IW, Altszuler N, Rifkin DB, Wilson EL, Davitz MA (1994) Release of GPI-anchored membrane proteins by a cell-associated GPI-specific phospholipase D. EMBO J 13:1741-1751.

Mikol DD, Gulcher JR, Stefansson K (1990) The oligodendrocytemyelin glycoprotein belongs to a distinct family of proteins and contains the HNK-1 carbohydrate. J Cell Biol 110:471-479.

Moos M, Tacke R, Scherer H, Teplow D, Fruh K, Schachner M (1988) Neural adhesion molecule $\mathrm{L} 1$ as a member of the immunoglobulin superfamily with binding domains similar to fibronectin. Nature 334: 701-703.

Noda M, Yoon K, Rodan GA, Koppel DE (1987) High lateral mobility of endogenous and transfected alkaline phosphatase: a phosphatidylinositol-anchored membrane protein. J Cell Biol 105:1671-1677.

Palay SL, Chan-Palay V (1974) The cerebellar cortex: cytology and organization. New York: Springer.

Paterson JA, Privat A, Ling EA, Leblond CP (1973) Investigations of glial cells in semithin sections. III. Transformation of subependymal cells into glial cells, as shown by radioautography after ${ }^{3} \mathrm{H}$-thymidine injection into the lateral ventricle of the brain of young rats. J Comp Neurol 149:83-103

Pimenta AF, Zhukareva V, Reinoso B, Grimley C, Henzel B, Fischer I, Leavitt P (1993) Cloning the limbic system-associated membrane protcin (LAMP): a ncw immunoglobulin supcrfamily member. Soc Neurosci Abstr 19:689a.

Ranscht B, Dours-Zimmerman MT (1991) T-Cadherin, a novel cadherin cell adhesion molecule in the nervous system lacks the conserved cytoplasmic region. Neuron 7:391-402.

Reichardt LF, Tomaselli KJ (1991) Extracellular matrix molecules and their receptors: functions in neural development. Annu Rev Neurosci 14:531-570.

Reid HH, Wilks AF, Bernard O (1990) Two forms of the basic fibroblast growth factor receptor-like mRNA are expressed in the developing mouse brain. Proc Natl Acad Sci USA 87:1596-1600.

Rosen CL, Lisanti MP, Salzer JL (1992) Expression of unique sets of GPI-linked proteins by different primary neurons in vitro. J Cell Biol 117:617-627.

Salzer JL, Colman DR (1989) Mechanisms of cell adhesion in the nervous systcm: rolc of the immunoglobulin gene superfamily. Dev Neurosci 11:377-390.

Salzer JL, Holmes WP, Colman DR (1987) The amino acid sequences of the myelin-associated glycoproteins: homology to the immunoglobulin gene superfamily. J Cell Biol 104:957-965.

Salzer J, Rosen CL, Struyk AF (in press) GPI anchored proteins in neural cell adhesion. In: Advances in cellular and molecular biology (Colman DR, ed). Greenwich, CT: Jai

Sambrook J, Fritsch EF, Maniatis T (1989) Molecular cloning: a laboratory manual. Cold Spring Harbor, NY: Cold Spring Harbor Laboratory.

Sanger F, Nicklen S, Coulson AR (1977) DNA sequencing with chainterminating inhibitors. Proc Natl Acad Sci USA 74:5463-5467.

Schofield PR, McFarland KC, Hayflick JS, Wilcox JN, Cho TM, Roy S, Lee NM, Loh HH, Seeburg PH (1989) Molecular characterization of a new immunoglobulin superfamily protein with potential roles in opioid binding and cell contact. EMBO J 8:489-495.

Seeger MA, Haffley L, Kaufman TC (1988) Characterization of amalgam: a member of the immunoglobulin gene superfamily from Drosophila. Cell 55:589-600.

Seldin MF, Saunders AM, Rochelle JM, Howard TA (1991) A proximal mouse Chromosome 9 linkage map that further defines linkage groups homologous with segments of human chromosomes 11,15 , and 19. Genomics 9:678-685.

Shibuya M, Sachiko Y, Yamane A, Ikeda T, Tojo A, Matsushime H, Sato M (1990) Nucleotide sequence and expression of a novel human receptor-type tyrosine kinase gene $(f t)$ closely related to the fms family. Oncogene 5:519-524.

Shoemaker MO, Lau W. Shattuck RL, Kwiatkowski AP, Matrisian PE, Geurra-Santos L, Wilson E, Lukas TJ, Eldick LJV, Watterson DM (1990) Use of DNA sequence and mutant analyses and antisense oligodeoxynucleotides to examine the molecular basis of nonmuscle myosin light chain kinase autoinhibition, calmodulin recognition, and activity. J Cell Biol 111:1107-1.125.

Silver J (1985) Confidence limits for estimates of gene linkage based on analysis of recombinant inbred strains. J Hered 76:436-440.

Stahl B, Müller B, Boxberg Yv, Cox EC, Bonhoeffer F (1990) Biochemical characterization of a putative axonal guidance molecule of the chick visual system. Neuron 5:735-743.

Stefanová I, Horejsí V, Ansotegui IJ, Knapp W, Stockinger H (1991) GPI-anchored cell-surface molecules complexed to protein tyrosine kinases. Science 254:1016-1019.

Stoeckli ET, Kuhn TB, Duc CO, Ruegg MA, Sonderegger P (1991) The axonally secreted protein axonin- 1 is a potent substratum for neurite growth. J Cell Biol 112:449-455.

Su B, Waneck GL, Flavell RA, Bothwell AL (1991) The glycosyl phosphatidylinositol anchor is critical for Ly-6A/E-mediated T cell activation. J Cell Biol 112:377-384.

Takeichi M (1990) Cadherins: a molecular family important in selective cell adhesion. Annu Rev Biochem 59:237-252.

Taylor BA (1978) Recombinant inbred strains. In: Origins of inbred mice (Morse IHC, ed), pp 423-438. New York: Academic.

Tse AGD, Barclay AN, Watts A, Williams AF (1985) A glycophospholipid tail at the carboxy terminus of the Thy-1 glycoprotein of neurons and thymocytes. Science 230:1003-1008.

Yamawaki-Kataoka Y, Nakai S, Miyata T, Honjo T (1982) Nucleotide sequence of gene segments encoding membrane domains of immunoglobulin g chains. Proc Natl Acad Sci USA 79:2623-2627.

Zacco A, Cooper V, Chantler P, Fisher-Hyland S, Horton HL, Levitt P (1990) Isolation, biochemical characterization and ultrastructural analysis of the Limbic System-Associated Membrane Protein (LAMP), a protein expressed by neurons comprising functional neural circuits. J Neurosci 10:73-90.

Zhukareva V, Levitt P (1993) LAMP: a novel GPI-linked protein involved in cell-to-substratum adhesion by specific populations. Soc Neurosci Abstr 19:535.7. 